NBSIR $73 \cdot 125$

\title{
Interlaboratory Evaluation of the Tunnel Test (ASTM E 84) Applied to Floor Coverings
}

T. G. Lee and Clayton Huggett

Institute for Applied Technology

National Bureau of Standards

Washington, D. C. 20234

March 1973

Final Report

Prepared for

Social Security Administration

Health Services \& Mental Health Administration

Department of Health, Education, \& Welfare

Washington, D. C. 20201 



\section{INTERLABORATORY EVALUATION OF THE TUNNEL TEST (ASTM E 84) APPLIED TO FLOOR COVERINGS}

T. G. Lee and Clayton Huggett

Institute for Applied Technology

National Bureau of Standards

Washington, D. C. 20234

March 1973

Final Report

Prepared for:

Social Security Administration

Health Services \& Mental Health Administration

Department of Health, Education, \& Welfare

Washington, D. C. 20201

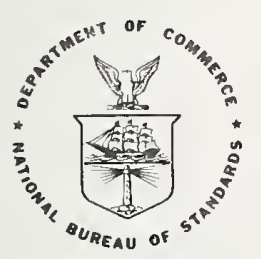

U. S. DEPARTMENT OF COMMERCE, Frederick B. Dent, Secretary

NATIONAL BUREAU OF STANDARDS, Richard W. Roberts, Director 



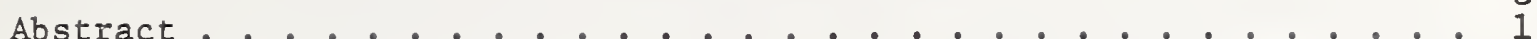

1. Introduction . . . . . . . . . . . . . . . . . . 2

2. The ASTM E 84-70 Test Method ................ . 3

3. Interlaboratory Evaluation of Test Method . . . . . . . . . 5

3.1 Participants . . . . . . . . . . . . . 6

3.2 Test Materials . . . . . . . . . . . . . 9

3.3 Experimental Design . . . . . . . . . . . . . . 11

4. Survey Results . . . . . . . . . . . . . . . . 13

4.1 Physical Characteristics of Furnaces . . . . . . . . . 13

4.1.1 Furnace Windows. . . . . . . . . . . . 13

4.1.2 Location of Manometer and Photometer . . . . . . 14

4.1.3 Draft Control . . . . . . . . . . . 14

4.1.4 Furnace Air Velocity and Temperature . . . . . . . 15

4.1.5 Thermocouple Type and Mounting . . . . . . . 16

4.1.6 Relative Humidity of Intake Air . . . . . . . 16

4.2 Illustration of Furnace Characteristics . . . . . . . 17

5. Results of Tests . . . . . . . . . . . . . . . 23

5.1 Statistical Results . . . . . . . . . . . 29

5.2 The Use of Other Formulas for FSC Calculation . . . . . 31

6. Discussion . . . . . . . . . . . . . . . 33

6.1 Tunnel Construction Variables... . . . . . . . . . 33

6.2 Results of Flame Spread Measurement . . . . . . . . 37

6.3 Effect of Using Single Formulas for FSC Calculation . . . 39

7. Conclusions. . . . . . . . . . . . . . . . 43

8. Recommendations. . . . . . . . . . . . . . . . 44 
9. Acknowledgement . . . . . . . . . . . . . . . 46

Appendix A. Sample Data Sheet . . . . . . . . . . . . . . 47

Appendix B. Dimensions of ASTM E 84 Furnace . . . . . . . . . . . 48

Appendix C. Task Groups Under ASTM E5.04 to Study Revision of

E 84 Standard . . . . . . . . . . . . . 49

Appendix D. Method of FSC Calculation, Current E 84-70 Standard . . 50

Appendix E. Calculation of Reproducibility . . . . . . . . . . 51

References . . . . . . . . . . . . . . . . . 52

\section{List of Illustrations}

1. Representative E84 Tunnels . . . . . . . . . . . . . 17

2. Representative E84 Tunnels . . . . . . . . . . . . . 18

3. Examples of Smoke Meter Locations . . . . . . . . . . . . 19

4. Examples of Thermocouple Mountings . . . . . . . . . . 20

5. Examples of Windows and Bricks . . . . . . . . . . . . 21

6. Examples of Burners . . . . . . . . . . . . . . . 22

7. Mean FSC of Each Lab versus Mean of All Labs . . . . . . . . 24

8. FSC as Function of Density for Material 非 . . . . . . . . . 40

9. Distance-Time Plot of Typical Test for Nine Materials . . . . 42

List of Tables

1. Participants in the Interlaboratory Evaluation . . . . . . 7

2. Test Materials . . . . . . . . . . . . . . . 8

3. Survey Results on Selected Characteristics . . . . . . . . 12

4. Data on Flame Spread (FSC) . . . . . . . . . . . . 25

5. Data on Smoke . . . . . . . . . . . . . . 26

6. Data on Fuel Contribution . . . . . . . . . . . . . 27 
T. G. Lee and Clayton Huggett

Results of an interlaboratory evaluation of the ASTM E 84 tunnel test method involving eleven laboratories and nine materials, including four carpets, are reported. Data on flame spread, smoke, and fuel contribution are analyzed statistically. Selected physical characteristics of each tunnel are tabulated and compared relative to specifications in the test method. The between-laboratory coefficient of variation (reproducibility) in flame spread classification (FSC) was found to range from 7 to $29 \%$ for the four carpets and from 18 to $43 \%$ for the other materials tested. The between-laboratory coefficients of variation for smoke developed and fuel contribution ranged from 34 to $85 \%$ and from 22 to $117 \%$ respectively for all materials tested. The causes of higher variability in smoke and fuel contribution measurement between laboratories is not definitely known but may reasonably be attributed to variations in tunnel construction, maintenance, and operation, in the location of photometers, and in the mounting of thermocouples in different laboratorles. Some variability of results may possibly be due to variation in test specimens. Variation in construction and measurement techniques among tunnels may be minimized by updating the test method standard.

Key words: ASTM E84; building materials; carpets; fire tests; flame spread tests; interlaboratory evaluation; round-robin; statistical analysis; test method standard. 


\section{Introduction}

Practically all building code requirements in the United States for control of the flamability of interior surface finish materials are based on the ASTM E 84-70 [1]* twenty-five foot tunnel test method, also used in UL 723, NFPA No. 255-1972 and ANSI A2.5-1970. The reproducibility and appropriateness of the method have not been seriously questioned in the past because the tests were conducted by only two or three laboratories and limited to traditional construction materials. With the recent increase in the number of laboratories with facilities for this type of testing, the widespread use of new types of materials (i.e. thermoplastic and other synthetics), and recent application to carpets, certain inconsistencies in test results have been reported. This has raised serious questions by some safety experts and by certain segments of industry as to the use of the E 84 test for floor covering and other interior finish materials.

Some of the questions which have been raised in regard to the tunnel flame spread test merit technical consideration and are being studied at the National Bureau of Standards (NBS) in cooperation with the Department of Health, Education and Welfare (HEW). The following aspects of the test are of primary concern:

1. the variability of results among different laboratories,

*Figures in brackets indicate the literature reference at the end of the paper. 
2. the merit of the test method for evaluating flooring materials since the test requires mounting a flooring specimen in a ceiling position in the test furnace, and

3. the use of four different formulas to derive the flame spread classification.

The question of variability of the test results is the principal subject of this report, which deals with the reproducibility (among laboratories) and repeatability (within laboratories) of the test method based on round-robin tests of selected materials. The report also gives survey results on physical features of each tunnel and some of the deviations from the published standard method.

\section{The ASTM E 84-70 Test Method}

The purpose of the test is to determine the comparative surface burning characteristics of material under test by evaluating
(1) flame spread;
(2) fuel contributed; and
(3) smoke developed.

The test establishes a basis on which surface burning characteristics of different materials may be compared.

A specimen 20 inches wide x 25 feet long, usually in three sections, is mounted and supported on the top ledge of a long test chamber. The chamber consists of a masonry (fire brick) insulated horizontal tunnel having an inside width of 17.5 inches, a height of 12 inches, and a length of 25 feet. The tunnel is open at both ends, the "fire" and "vent" ends. The specimen in a ceiling position, with the side to be tested facing down, is subjected to diffusion flames from two gas burners pointing upward at the fire end. Forced draft induced by a 
blower and damper system at the "vent" end of the tunnel pulls air through a small air inlet upstream from the burners into the fire end. A prescribed average velocity measured at the vent end prior to ignition is required. After ignition, a constant negative pressure (draft) is maintained and controlled by the damper system. The flame and draft serve to ignite the specimen and to induce flame spread along the ceiling of the tunnel. Windows located on the side of the tunnel allow an observer to record the extent of flame spread as a function of time. The flame spread classification (FCS) is based on a scale which has 0 for asbestos-cement board and 100 for select grade of red oak flooring. It takes into consideration the distance or time of flame spread by using one of four formulas.

The smoke developed is measured by a photometer system located some distance downstream from the "vent" end. The 10 minute integration of the time versus percent light obscuration curve from the photometer reading forms the basis for reporting smoke developed, again relative to the scale of asbestos-cement board as 0 and red oak as 100 .

The fuel contribution is determined by the increase in the flue gas temperature at the "vent" end. It is based on the 10 minute integration of time versus temperature curve of the flue thermocouple output during the test relative to the scale of asbestos-cement board as 0 and red oak as 100 .

The test conditions in the tunnel, air supply, and specimen conditioning are controlled and/or recorded by various instruments. However, certain details relating to materials of construction, instrumentation and control are not included in the standard. No 
mention is made of the expected precision of the method or of the number of tests required, for example. As a result, there is considerable variation in tunnel design and procedures among laboratories using the E 84 method. These problems have been referred to Comittee E 5.04 of ASTM for resolution in the past. At present there are six task groups studying various aspects of the problem (see appendix C).

3. Interlaboratory Evaluation of Test Method

To obtain a realistic estimate of the variability of the test method as it is performed by the individual laboratories, a collaborative study sponsored jointly by HEW and NBS was initiated. Eleven (11) laboratories known to have a tunnel facility in this country and Canada agreed to participate. Available data on previous round-robins, though limited to only a few laboratories [2], and the effects of the test method variables [3, 4] were reviewed prior to this study.

A meeting, attended by representatives from nine of the part1cipating laboratorles, was held in October 1971 to discuss the detailed procedures. At this meeting a suggestion was made to specify additional calibration and measurement techniques not mentioned in the test method. This was countered by others who held that the purpose of the round-robin was to evaluate existing test practices in the various laboratories and not to develop a new version of the test.

The procedure finally adopted was for all laboratories to follow the E-84-70 test procedure to the extent practicable. Where deviations were necessary. or where detailed procedures were lacking, each laboratory was to follow its own normal test procedures and provide notes on the deviations and individual interpretations. The furnace leakage test of 
paragraph 4.2 of the method was required and smoke bombs were made available to each laboratory for pinpointing the leakage area if any.

Since the mounting of carpet specimens was a probable source of laboratory variability and is not specified by the method, all mounting on a backing board was performed by NBS before the materials were distributed. A prescribed randomized test sequence and detailed instructions were supplied to the participating laboratories. A uniform data sheet was also provided. A 2-minute sample presoak (specimen loading time) before starting the test was required to help standardize the test procedure. A representative from NBS also visited each laboratory to make air velocity measurements using a single calibrated anemometer, to survey physical characteristics of the facilities, and to witness selected tests.

The procedures agreed upon were designed to give results based essentially on the current practices of each laboratory and also to provide a basis for comparing the effects of deviations for possible future modification of the method. A supplemental questionnaire, prepared by Underwriters' Laboratories, Inc. (UL) was sent to each laboratory to help pinpoint the differences in construction and methodology among the facilities.

\subsection{Participants}

A total of 11 laboratories collaborated in this joint study. The 1ist of participants and laboratory abbreviations are given in Table 1. The degree of experience in using the test method among laboratories varies from less than a year to over 20 years. Some laboratories (UL, UL/SAN, UL/CAN, NRC, SwRI, AMB, FM) test primarily for the public 
Table 1. Participants of Interlaboratory Evaluation of the ASTM E-84 Test Method

Mr. Tom Castino

Underwriters' Laboratories, Inc.

Abbrerriation

UL

Northbrook, Illinois 60062

Mr. Alex Briber

Underwriters' Laboratories, Inc.

UL/SAN

Santa Clara, California 95050

$\mathrm{Mr}$. Norman Pearce

Underwriters' Laboratories of Canada

$\mathrm{UL} / \mathrm{CAN}$

Scarborough, Ontario, Canada

Mr. Calvin H. Yuill

Southwest Research Institute

SWRI

San Antonio, Texas 78228

Mr. A. Rose

National Research Council

NRC

Ottawa 7, Ontario, Canada

Mr. D. R. Crawford

WEY

Weyerhauser Company

Longview, Washington, 98632

Mr. W. A. Ranzenberger

Technical Center

OCF

Owens Corning Fiberglas

Granville, Ohio 43023

Mr. Robert Friedheim

NG

National Gypsum Research Laboratories

Buffa10, New York 14217

Mr. P. G. Gott

Factory Mutual Research Corporation

FM

Norwood, Massachusetts 02062

Mr. Lewis G. Bricker

Ambric Testing and Engineering Association

$A M B$

Philadelphia, Pennsylvania

Mr. Robert Robins

Hardwood Plywood Manufacturing Association

HPMA

Arlington, Virginia 
TABLE 2, TEST MATERIALS,BACKING, AND ADHESIVE $\stackrel{\text { a/ }}{\text { a }}$

\begin{tabular}{|c|c|c|c|c|c|}
\hline \multirow[b]{2}{*}{$\begin{array}{l}\text { Specimen } \\
\text { Number }\end{array}$} & \multirow[b]{2}{*}{ Materia1 } & \multirow{2}{*}{$\begin{array}{l}\text { Nominal } \\
\text { Thickness } \\
\text { in } \\
\end{array}$} & \multicolumn{2}{|c|}{ Density } & \multirow[b]{2}{*}{ Description. } \\
\hline & & & $1 \mathrm{~b} / \mathrm{ft} \mathrm{t}^{2}$ & $\mathrm{oz} / \mathrm{yd}^{2}$ & \\
\hline 0 & Red Oak Flooring & $25 / 32$ & 2.8 & & $\begin{array}{l}\text { NOFMA certified, Ozark } \\
\text { brand, clear plain top grade } \\
\text { Bismarck mil1, } 21 / 4^{\prime \prime} \text { wide } \\
\text { tongue and groove. }\end{array}$ \\
\hline 1 & Glass Fiber Batts & 1 & 0.11 & & $\begin{array}{l}\text { Exposed surface, Neoprene } \\
\text { coated. }\end{array}$ \\
\hline 2 & Sheet viny 1 & $3 / 32$ & 0.64 & & $\begin{array}{l}\text { filled vinyl surfaces, in- } \\
\text { organic felt backed. }\end{array}$ \\
\hline 3 & $\begin{array}{l}\text { Lauan Plywood } \\
\text { Unfinished }\end{array}$ & $3 / 16$ & 0.45 & & Sanded, $4.4 \mathrm{~mm}, 3 \mathrm{ply}$ panel. \\
\hline 4 & Carpet A & $5 / 16$ & & 81 & $\begin{array}{l}\text { Woven, level loop, Jute } \\
\text { backing, pile } 38 \text { oz/yd } \\
\text { Acrylic, brown. }\end{array}$ \\
\hline 5 & Carpet $B$ & $1 / 2$ & & 64 & $\begin{array}{l}\text { Tufted shag, } 1 \text { 1/8" length } \\
\text { tuft, pile } 24 \text { oz/yd , jute } \\
\text { backing, Nylon }\end{array}$ \\
\hline 6 & $\begin{array}{l}\text { Carpet } A+ \\
\text { Underlayment }\end{array}$ & $\begin{array}{l}5 / 16 \\
1 / 2\end{array}$ & & $\begin{array}{l}81 \\
56\end{array}$ & $\begin{array}{l}\text { Same as \#4 } \\
\text { Rubberized hair felt pad. }\end{array}$ \\
\hline 7 & Carpet C & $3 / 8$ & & 86 & $\begin{array}{l}\text { Tufted, leve1 10op, pile } 20 \\
\text { oz/yd } 2 \text {, Nylon, } 1 / 8^{\prime \prime} \text { foam rubber } \\
\text { attached pad. }\end{array}$ \\
\hline \multirow[t]{3}{*}{8} & $\begin{array}{l}\text { Paperboard } \\
\text { (corrugated) }\end{array}$ & 0.14 & 0.17 & & $\begin{array}{c}125 \text { \# Test, B flute, Brown } \\
\text { (corrugated) paper. }\end{array}$ \\
\hline & $\begin{array}{l}\text { Asbestos-Cement } \\
\text { Board }\end{array}$ & $1 / 4$ & 2.5 & & Flexboard, Type F. \\
\hline & $\begin{array}{l}\text { Adhesive for } \\
\text { carpets }\end{array}$ & $0.13 \mathrm{lb} / \mathrm{ft}^{2}$ & applied & & $\begin{array}{l}\text { A.P. Green Insulation (silicate) } \\
\text { adhesive for mounting car- } \\
\text { pet to ACB board. }\end{array}$ \\
\hline
\end{tabular}

a/ All specimen sections were $20.5 \times 96$ inches, except \#1. 
whereas others $11 \mathrm{mlt}$ their activities to research and development work for their own company (WEY, OCF, HPMA, and NG)*. The laboratories are identified in the report by code letters only, the usual practice in round-robin studies.

\subsection{Test Materials}

In order to obtain meaningful results and yet not to burden the participating laboratories with an excessive amount of testing, the selection of materials was made by consultation with the participants. Table 2 gives the relevant data on the materials and the adhesive selected for the program. The materials selected represent common construction and flooring materials, which included simple and composite plastic, cellulosic and inorganic-base materials, varying in thickness from 0.09 to 1 inch. The four carpet systems selected included two types of synthetic fiber, woven and tufted level loop as well as tufted shag construction, separate underlayment as well as integral foam backing, and an identical carpet both with and without underlayment. The materials exhibited various forms of physical response to fire exposure such as slow melting, fast shrinking, char formation, and delamination.

The expected flame spread classifications (FSC) for the materials span a wide range, from about 25 to 1000 . The test included materials with relatively similar flammability in order to determine the sensitivity of the method. All materials were obtained from commercial sources without special controls on uniformity except the plywood. All specimens were cut, randomized, and mounted when necessary, before

* HPMA and NG would also accept testings from the public. 
distribution. The carpets were cut parallel to the roll direction while wood specimens were supplied with grain parallel to their length.

All materials were cut into three 8 foot sections except the glass fiber batts which come in 25 foot rolls. Carpets were cemented to a standard $1 / 4$ inch thick asbestos cement board ( $\mathrm{ACB}$ ) using an adhesive (silicate) applied to the rough side of the board. For the carpet tested with underlayment the latter was first cemented to the ACB board and the carpet then stapled on top of the underlayment using 1 1/8" length staples spaced 10 inches apart in both directions (staple penetrates the underlayment only). Wire mesh screen (1-inch hexagonal chicken netting) laced with tie-wire in the back of $\mathrm{ACB}$ board covered the front of the specimen. The procedure of using either staples or wire mesh screen to prevent fallout is typical of practicing laboratories. The combination of staples and screening for these tests was intended to minimize separation between the carpet and underlayment, and thus to reduce a source of variability in test results.

Normally, sheet vinyl floor covering is adhered to the ACB board with an adhesive that would keep the flooring from delaminating from the substrate during the test, but for this work the material was treated as a thin laminate and procedure A1.8 in the test standard was followed. The procedure used consisted of placing 1/4" diameter steel rods, spanning the width of the tunnel at 2-ft intervals to support the specimen. A similar method was used on the glass fiber batt except that the rods were inserted through the center of the material. 
The densities of the plywood panel specimens are given in weight per $4 \times 8 \mathrm{ft}$ sheet. The density distribution is considered better than normal for commercial material of this type since about $20 \%$ of the panels from the high and low density ends of the lot were removed before distribution. The mean and calculated standard deviation for the material used are $14.5 \pm 1.3 \mathrm{lb} /$ panel for all the panels and $15.0 \pm 1.4 \mathrm{lb} / \mathrm{panel}$ for those used at the first section of the furnace. With some exceptions, the panel with the highest density among a set of three randomized specimens was placed at the fire end of the furnace.

Red oak flooring was purchased in a single lot from a mill in Bismarck, Missouri, randomized and distributed as reference material.

Though specimen selection and mounting were performed by NBS, specimen conditioning in accordance with the E-84 specification of $70 \pm 5^{\circ} \mathrm{F}$ and $35-40 \% \mathrm{RH}$ was performed by each laboratory. The moisture contents of the red oak specimens after conditioning were also reported.

\subsection{Experimental Design}

Each laboratory began the test program with 3 specimens of red oak, a reference material supplied by NBS. If the calibration test results were within the expected range in flame spread based on past experience $(100 \pm 5)$, the laboratory was to proceed to test other materials following the test sequence table assigned by NBS. The table was based on randomization of 21 tests ( 3 replicates and 7 materials) for each of the 11 laboratories. Individual laboratories were allowed to choose, prior to the testing program, an option of 2 or 3 replicate runs per material. Most performed 3 replicate runs, giving a total of 210 out of a possible 231 tests, excluding red oak. 


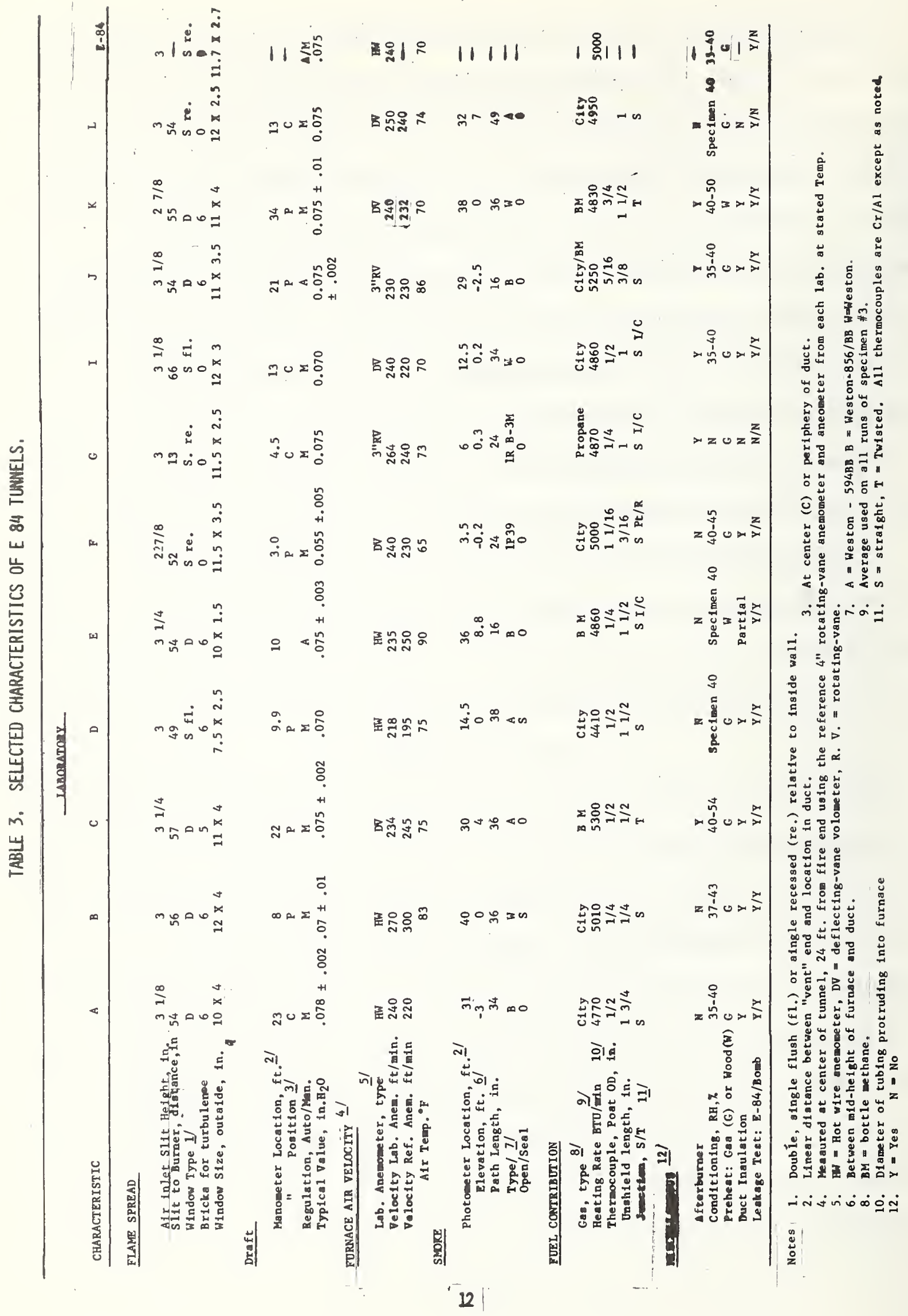


A total of 8 materials including 4 carpet systems were used in the test program. Two carpet systems and 4 other materials were tested by all 11 laboratories, one carpet system by 5 laboratories and the othe carpet by the remaining 6 laboratories. A comprehensive data sheet, based on suggestions from participants, was required for each test. A sample is shown in Appendix A.

\section{Survey Results}

\subsection{Physical Characteristics of Furnaces}

Selected tunnel characteristics of each laboratory are listed in Table 3. These were obtained by direct measurement during the authors' visits to the laboratories and by data furnished by the tunnel operator.

It is not the purpose of this study to show correlation, if any, between any of the characteristics and test reproducibility. But these data should form a useful basis for comparing each tunnel with the present E 84 requirements and for possible use in future revision of the test method standard.

\subsubsection{Furnace Windows}

According to Table 3 , only 3 laboratories conformed to the specified description of windows, namely of the single, recessed type. (See Appendix $B$ for a sketch of the furnace required by the Standard). Others used double or single flush (inside) windows. The purpose of adopting double windows was to reduce air leakage and possibly smoke deposits on windows to improve observation. To compensate for the loss of flow turbulence in the tunnel where the recessed part of the window is covered in the double type window, a common practice is to introduce 5 or 6 bricks (position not standardized) at intervals on the wall 
and floor edges along the tunnel. Experiments have shown that these bricks are necessary to meet the burning time requirement for the red oak standard reference material. Figure 5 shows the double-type window with brick (top) and the recessed-type window (bottom).

\subsubsection{Location of Manometer and Photometer}

The locations of the draft manometer to control flow and the photometer to measure smoke are not specified in the method. The drawing (Figure 1 in the Standard), shows that the photometer is further downstream from the "vent" end than the draft manometer. These distances from the "vent" end in the 11 tunnels listed in Table 3 varied from about 3 to about 34 feet for the manometers and from 3.5 to 40 feet for the photometers.

All photometers were oriented the same way, on a vertical axis, with the detector located at the bottom as indicated by the drawing in the standard.

\subsubsection{Draft Contro1}

The regulation of draft pressure in the tunnel may either be manual or automatic according to the method. A few laboratories used the automatic method. The response time of the regulator is not specified in the method. Automatic regulation is generally more consistent if not faster than manual regulation.

Data indicate that, depending on the type of material tested, variation in draft pressure within a single run is typically \pm .01 inch for a negative pressure of 0.075 inch of water. 


\subsubsection{Furnace Air Velocity and Temperature}

The method requires a linear air velocity of $240 \pm 5 \mathrm{ft} / \mathrm{min}$ average, measured at seven positions near the "vent" end. Most laboratories used a thermal anemometer or a deflecting vane type velometer for such measurements. Because of the continuous fluctuation of the pointer in these instruments caused by turbulent flow, the uncertainty in each reading is believed to be at least $\pm 15 \mathrm{ft} / \mathrm{min}$.

To measure air velocity variations among laboratories in this survey, a single 4 inch rotating vane-actuated anemometer (Bendix-Friez) was used. It was placed at the center, midheight and about one foot before the "vent" end of the tunnel. To observe dial readings through a tunnel window from the outside, a light source aimed at a small mirror mounted below the dial was also used.

The rotating vane type anemometer measures the total flow passing through its rotor while displaying the cumulative results on its dial, similar to gas meter. The calculated velocity is in itself an average over the time period of measurement and the cross sectional area within the 4 inch diameter. This type of anemometer, if calibrated, is believed to be more suitable in terms of precision and accuracy for the purpose.

The velocity data in Table 3 are only a comparison, at the time of measurement, of air flow values determined by the reference anemometer and anemometer of each laboratory. For the fire tests, the required $240 \pm 5 \mathrm{ft} / \mathrm{min}$ average velocity based on the regular measurement method of each laboratory was used. 
Furnace air temperature during velocity measurements by the reference and laboratory anemometers is also given in Table 3 . The test method is not explicit on the temperature at which velocity calibration is to be made. Experimental data by Robins [6] showed that velocity decreased about $12 \mathrm{ft} / \mathrm{min}$ (from 252 to 240) when air temperature increased $20^{\circ} \mathrm{F}$ (from $72^{\circ} \mathrm{F}$ to $92^{\circ} \mathrm{F}$ ) under a constant static pressure of $-0.075^{\prime \prime}$ water. The effect of temperature on velocity measurements at this range, though small, can be a source of error if not specified in the method. However, as pointed out by Armstrong [7] the practical effect would be insignificant in view of the extreme variation in temperature and hence velocity that exists after ignition and during the tests from one run to the next.

\subsubsection{Thermocouple Type and Mounting}

Aside from the diameter of the thermocouple wire the method does not specify type of junction, exposure length, mounting technique and size of the thermocouple post for flue gas measurement. A comparison of those parameters is also included in Table 3.

\subsubsection{Relative Humidity of Intake Air}

Temperature and relative humidity for the intake air to the tunnel furnace as well as for specimen conditioning are very specific in the standard. Many laboratories used a very elaborate system to maintain these conditions. However, some laboratories do not strictly adhere to the $35-40 \%$ relative humidity requirement at all times because of heavy testing schedules and/or adverse weather conditions. Data in Table 3 gives $\mathrm{RH}$ values based on typical reported values in the data sheets. Some laboratories only condition the specimens. 

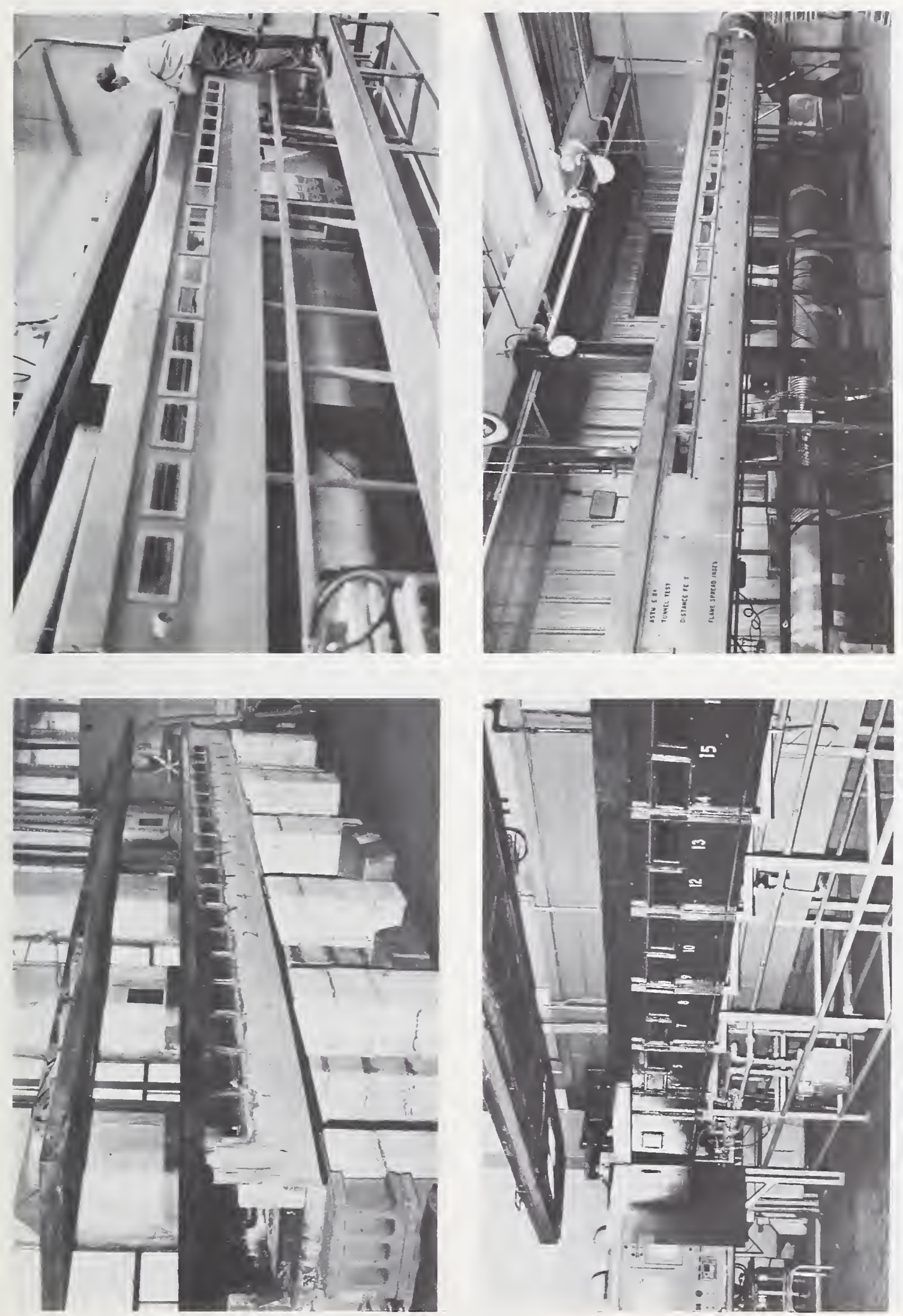

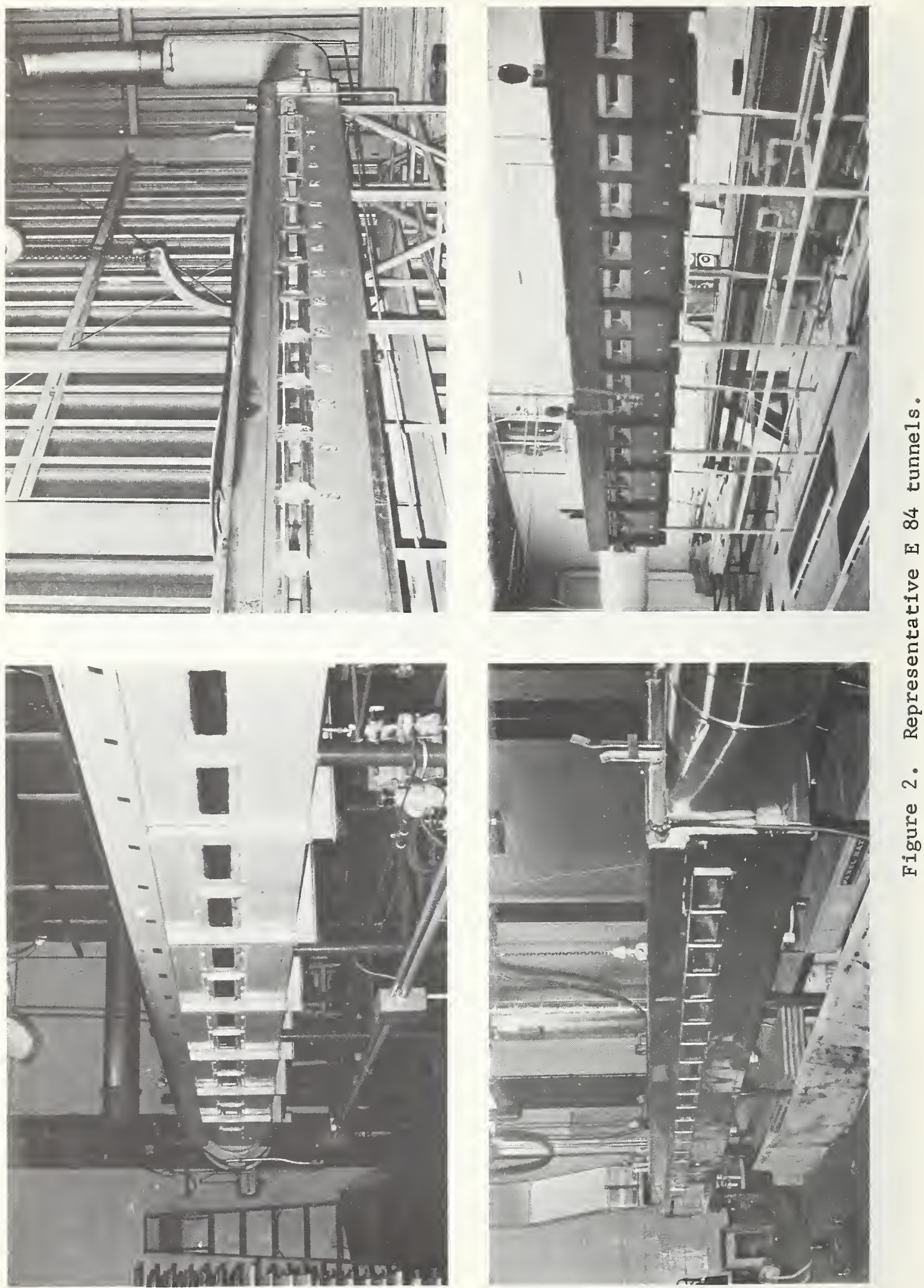

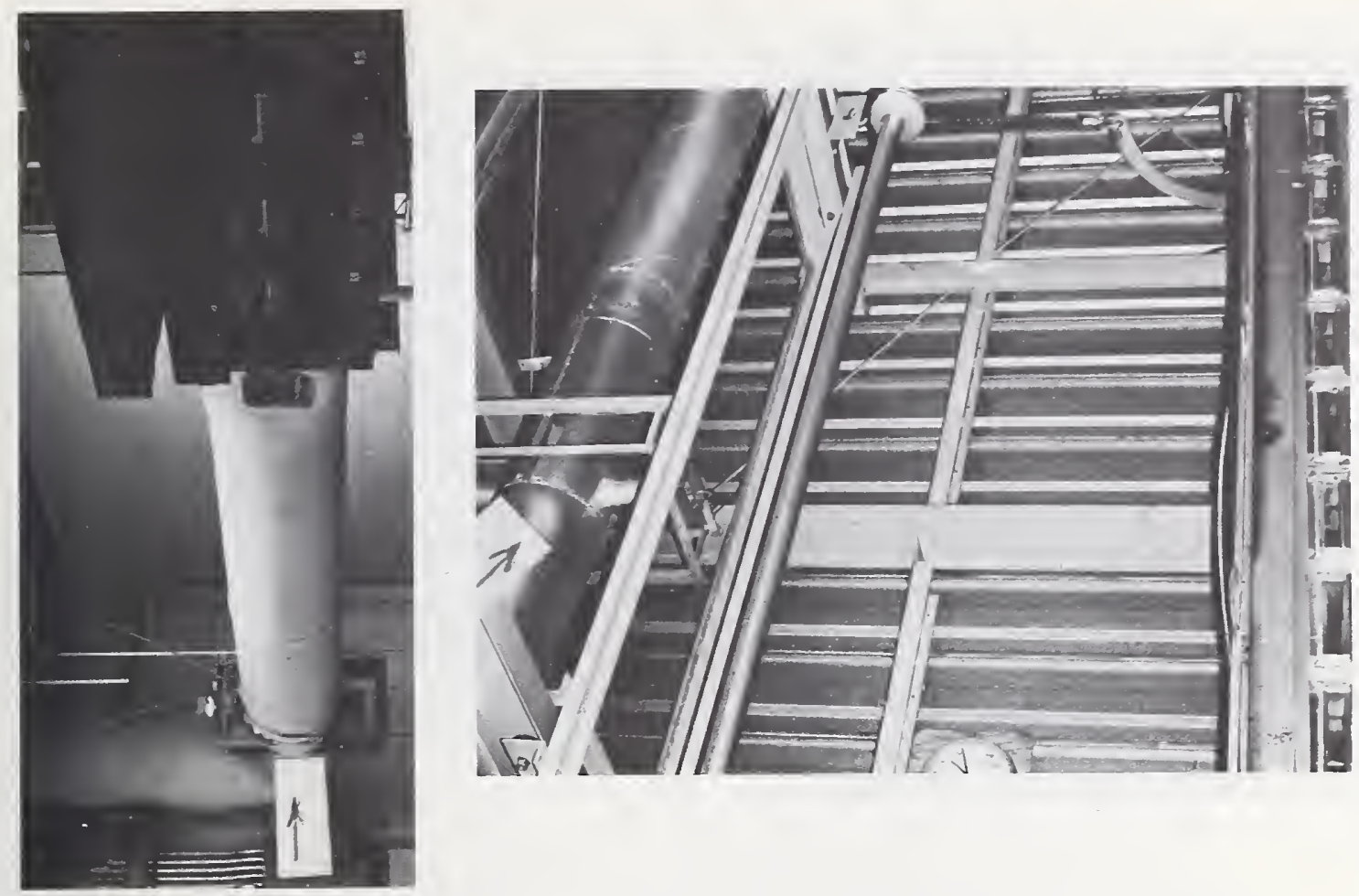

भू
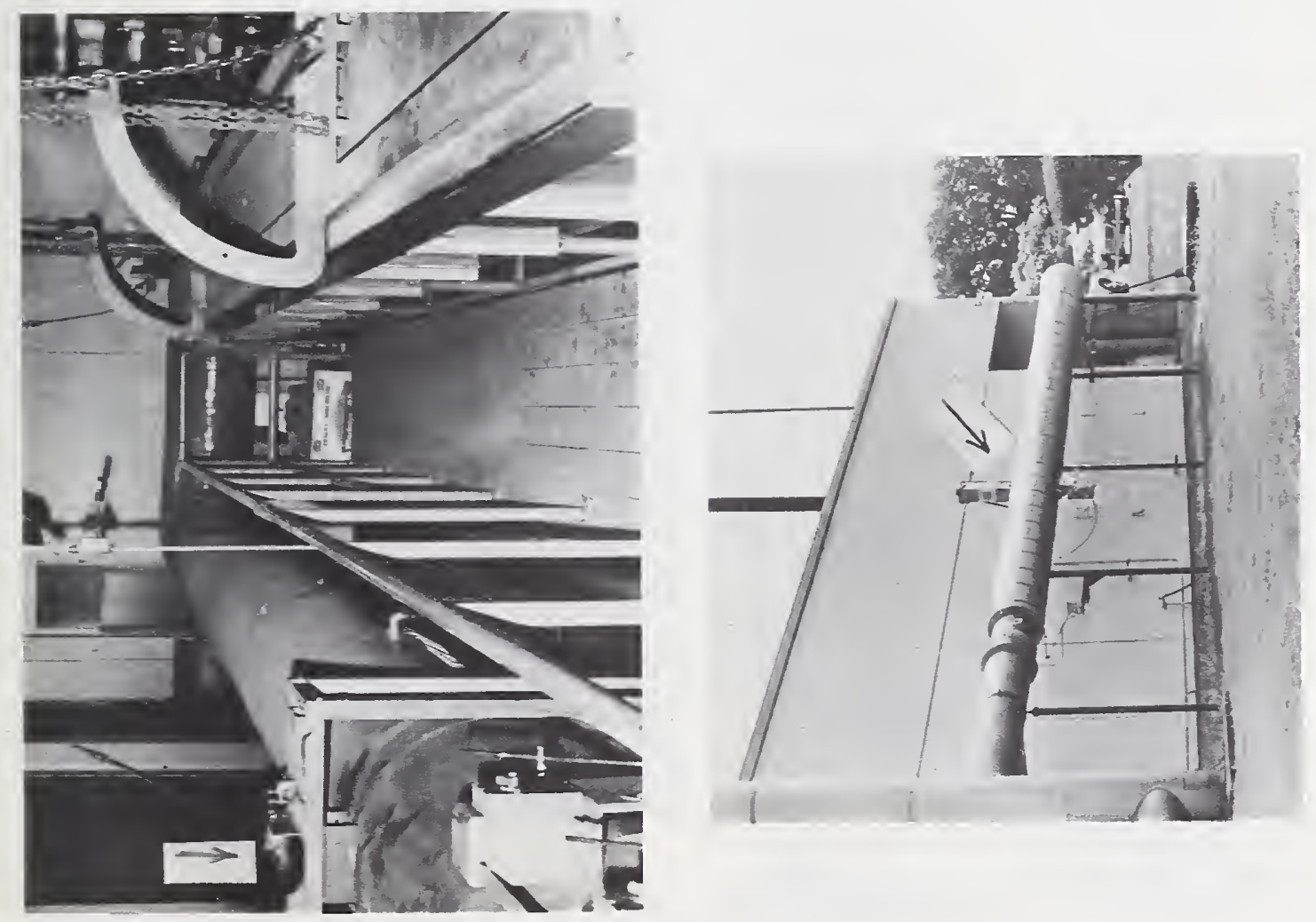

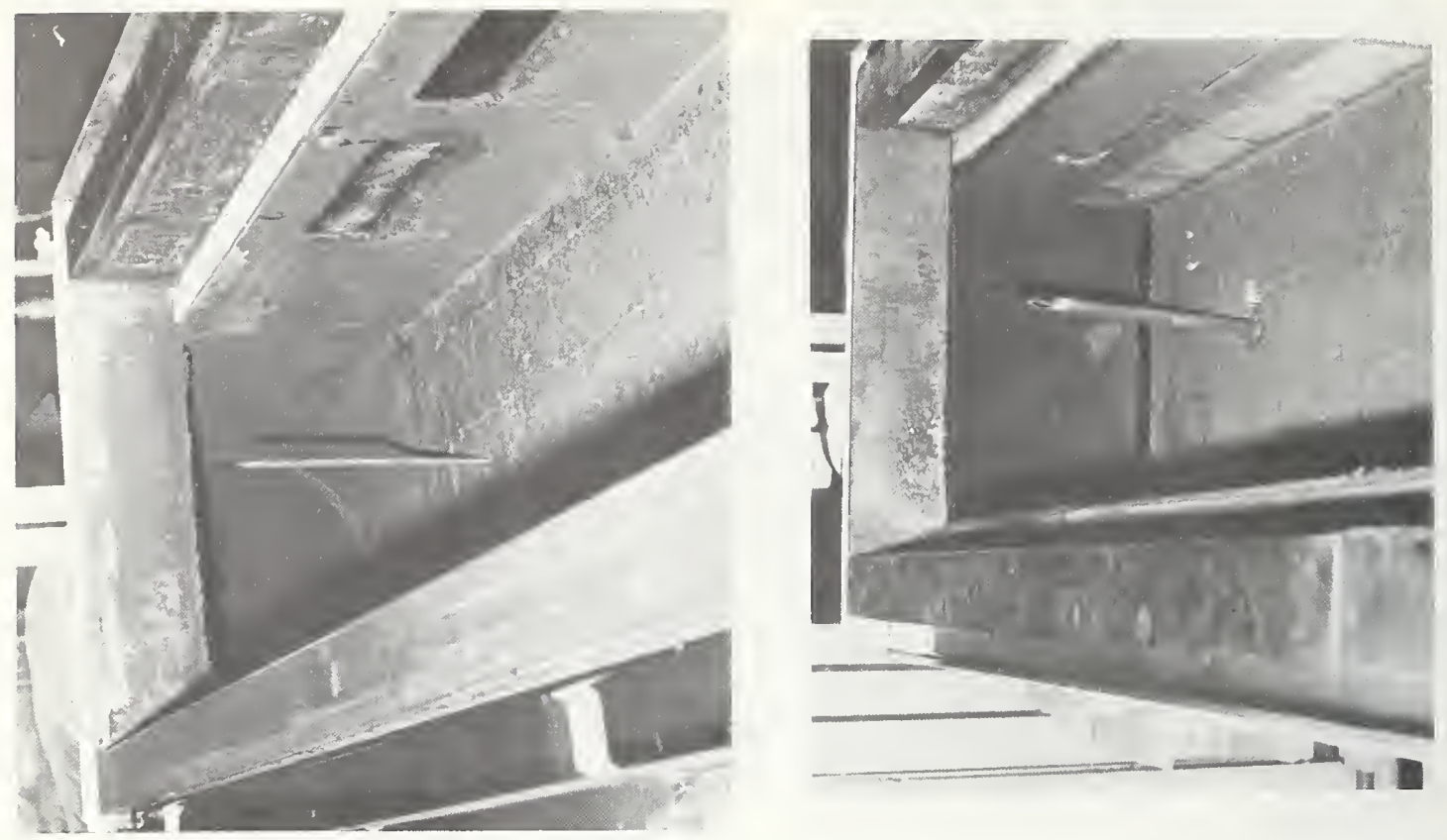

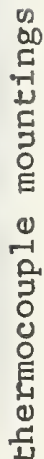
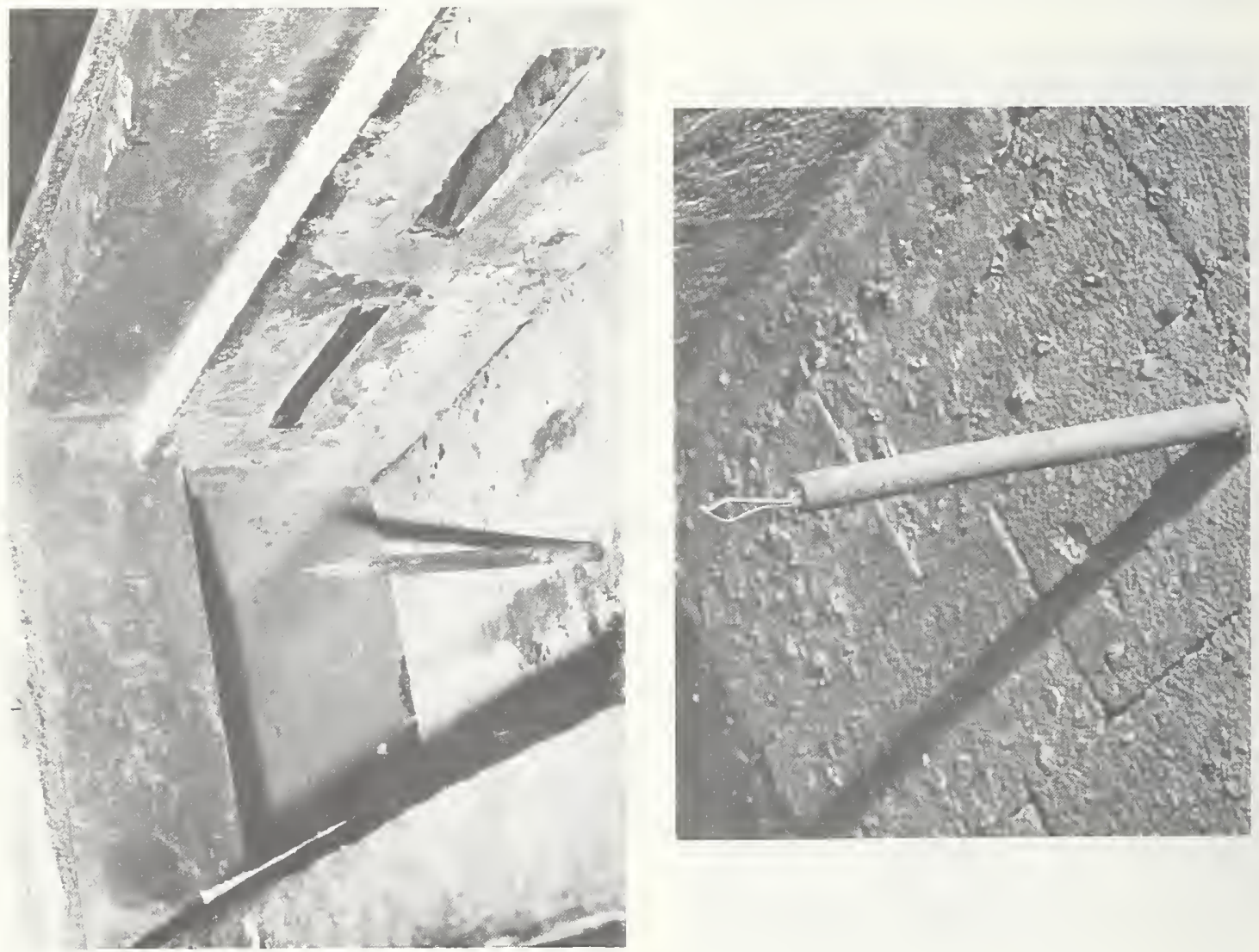

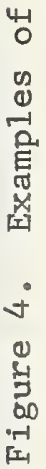



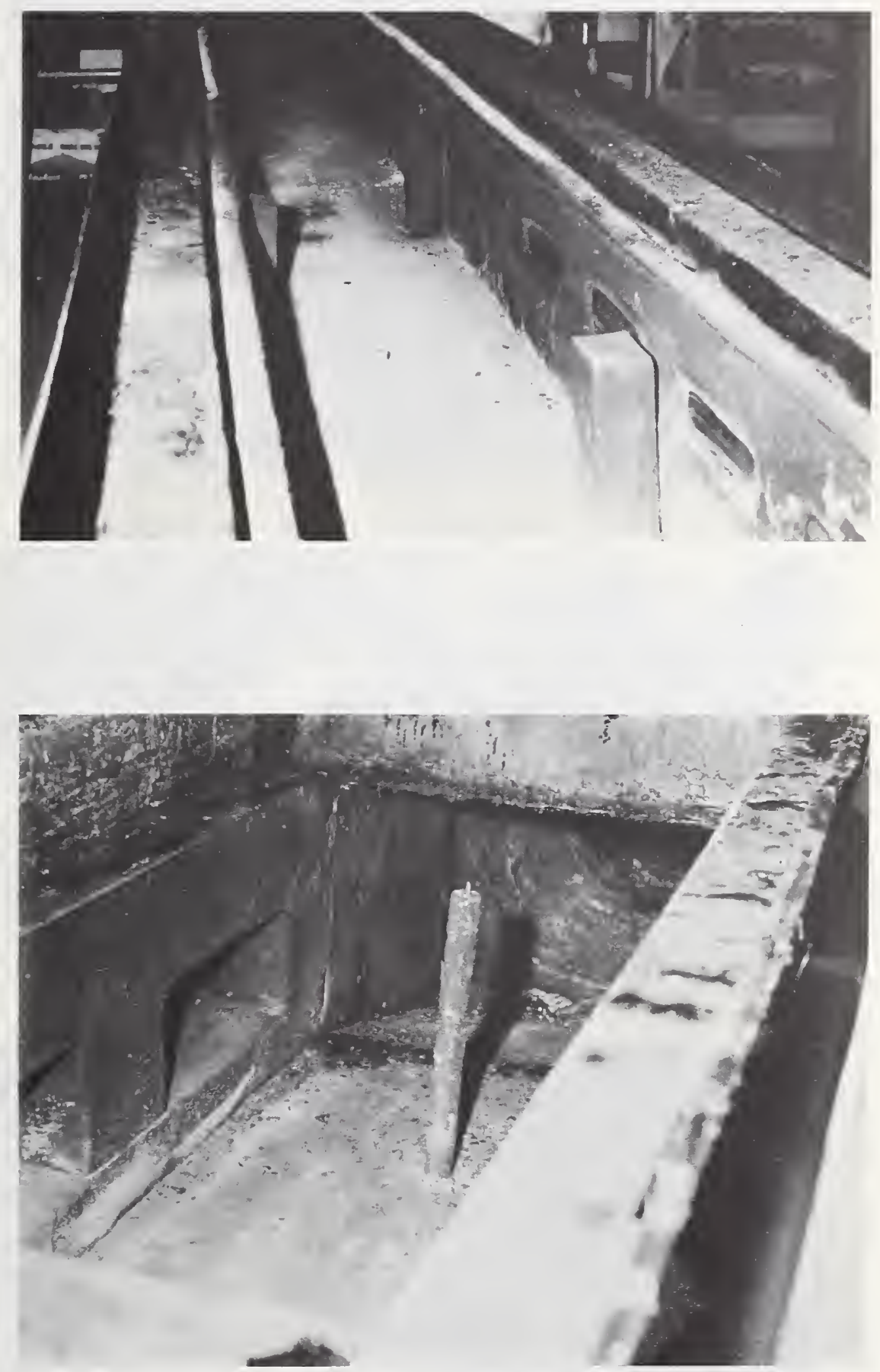

Figure 5. Examples of windows and bricks 

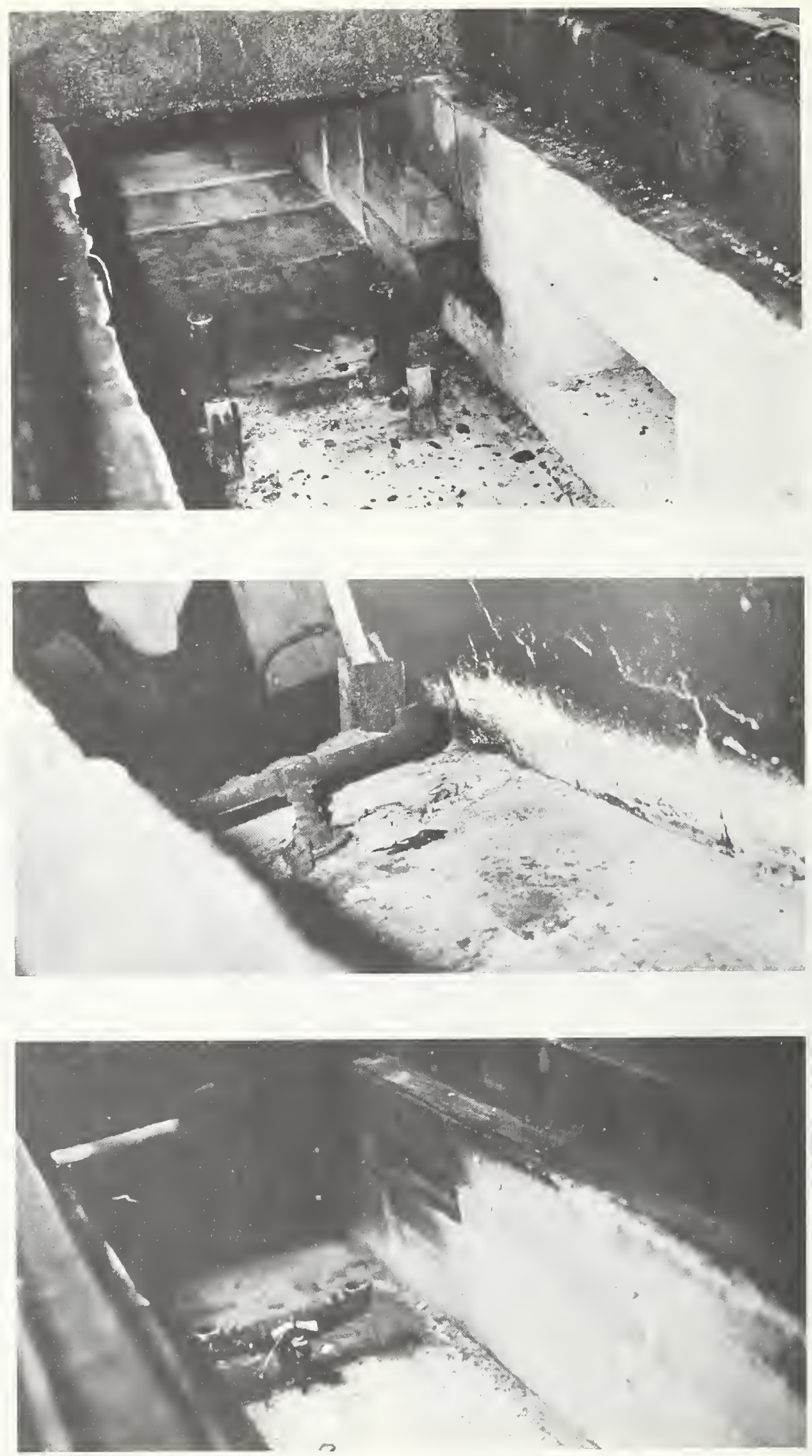

Figure 6. Examples of burners 


\subsection{Illustration of Furnace Characteristics}

Figures 1 and 2 are photographs showing overall views of the tunnels in eight (8) of the laboratories that participated in this study. Note the contrast between tunnels shown in the photographs. The variations of photometer locations (distance from "vent" end) and the elevation of the exhaust duct relative to the tunnel are illustrated in Figure 3. Figures 4 and 6 illustrate the variation in thermocouple and burners construction respectively among tunnels. The difference between singlerecessed windows and double type windows as well as the location of bricks for turbulence are shown in Figure 5.

\section{Results of Tests}

Data for flame spread classification, smoke developed, and fuel contribution from each laboratory are tabulated in Tables 4, 5, and 6 respectively. These were based on results calculated by the operator at each laboratory relative to his own red oak reference of 100 .

Figure 7 shows a plot based on the mean of all laboratories versus the means of each laboratory for flame spread of all materials.

Table 7 shows the moisture content, burning time, FSC, smoke, and fuel contribution of red oak reference material supplied by NBS. Except for one laboratory the FSC results are in general agreement with those obtained by each laboratory in their own calibration. The excepted laboratory (D) based its own calibration on red oak grown in a different region of the country relative to that used by others. The method of moisture measurement and moisture content limit for Red Oak reference are not specified in the standard. 


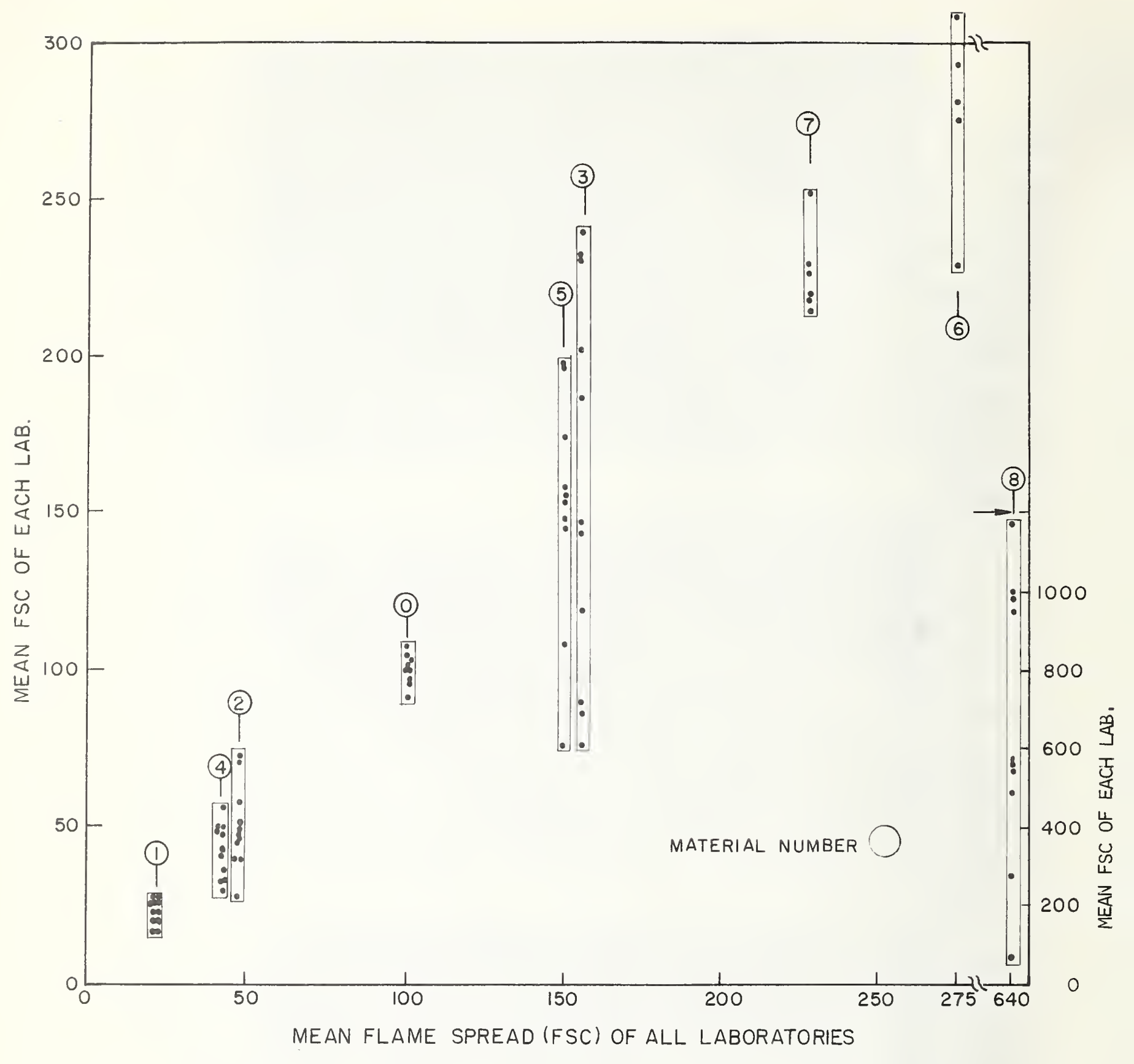

Figure 7. Mlean fSC OF EACH Lab, versus mean FSC OF aLL Laboratories, 
TABLE 4, TEST DATA ON FI_ANEE SPREAII (FSC).

\begin{tabular}{|c|c|c|c|c|c|c|c|c|c|}
\hline & & & & MATERIALS & & & & & \\
\hline Labs & 1 & 2 & 3 & 4 & 5 & 6 & 7 & 8 & 0 \\
\hline \multirow[t]{3}{*}{ A } & 23 & 44 & 262 & 36 & 176 & & 254 & 1100 & 99 \\
\hline & 26 & 49 & 231 & 28 & 135 & & 264 & 1320 & 93 \\
\hline & 23 & 44 & 220 & 33 & 145 & & 236 & 1100 & 95 \\
\hline \multirow[t]{3}{*}{ B } & 15 & 38 & 69 & 49 & 157 & 275 & & 74 & 100 \\
\hline & 15 & 38 & 170 & 46 & 157 & 275 & & 76 & 98 \\
\hline & 18 & 41 & 116 & & & & & & 98 \\
\hline \multirow[t]{3}{*}{ C } & 26 & 72 & 189 & 33 & 152 & & 208 & 580 & 95 \\
\hline & 26 & 69 & 185 & 77 & 147 & & 208 & 500 & 98 \\
\hline & 28 & 69 & 185 & 33 & 163 & & 226 & & 98 \\
\hline \multirow[t]{3}{*}{$\mathrm{D}$} & 23 & 51 & 122 & 36 & 145 & & 208 & 1100 & 86 \\
\hline & 23 & 46 & 71 & 36 & 143 & & 222 & 920 & 89 \\
\hline & 23 & 43 & 75 & 36 & $(367)$ & & 220 & 920 & 94 \\
\hline \multirow[t]{3}{*}{$E$} & 30 & 80 & 100 & 30 & 155 & & 220 & 510 & 97 \\
\hline & 25 & 70 & 75 & 35 & 140 & & 215 & 610 & 98 \\
\hline & 25 & 65 & 80 & & & & & & 98 \\
\hline \multirow[t]{3}{*}{$\mathrm{F}$} & 18 & 38 & 165 & 33 & 169 & & 232 & 72 & 108 \\
\hline & 21 & 38 & 74 & 54 & 179 & & 236 & 825 & 104 \\
\hline & 21 & 41 & 200 & 33 & 173 & & 220 & 550 & 98 \\
\hline \multirow[t]{3}{*}{ G } & 18 & 46 & 220 & 51 & 110 & 244 & & 440 & 105 \\
\hline & 18 & 46 & 183 & 46 & 100 & 200 & & 550 & 98 \\
\hline & 13 & 51 & 200 & 48 & 110 & 244 & & 733 & 100 \\
\hline \multirow[t]{3}{*}{ I } & (13) & 25 & 271 & 61 & 207 & 331 & & 1000 & 104 \\
\hline & 21 & 31 & 211 & 41 & 183 & 301 & & 1000 & 100 \\
\hline & 25 & 25 & 214 & 46 & 200 & 301 & & 1000 & 98 \\
\hline \multirow[t]{3}{*}{$\mathrm{J}$} & 26 & 39 & 77 & 41 & 197 & 289 & & 688 & 106 \\
\hline & 26 & 37 & 154 & 41 & 192 & 308 & & 56 & 102 \\
\hline & 27 & 40 & 196 & 44 & 199 & 284 & & 69 & 97 \\
\hline \multirow[t]{3}{*}{$\mathrm{K}$} & 23 & 54 & 77 & 23 & 73 & & 228 & & 100 \\
\hline & 23 & 59 & 73 & 33 & 73 & & 228 & & 100 \\
\hline & 23 & 57 & 75 & & & & & & \\
\hline \multirow[t]{3}{*}{$\mathrm{L}$} & 21 & 51 & 200 & 71 & $(367)$ & 275 & & 1000 & 90 \\
\hline & 21 & 51 & 190 & 41 & $(412)$ & 285 & & & 96 \\
\hline & 21 & 51 & & & & & & & \\
\hline
\end{tabular}

a/ Units based on red oak $=100$. 
TABLE 5, TEST DATA ON SFOKF LEVELOPED a

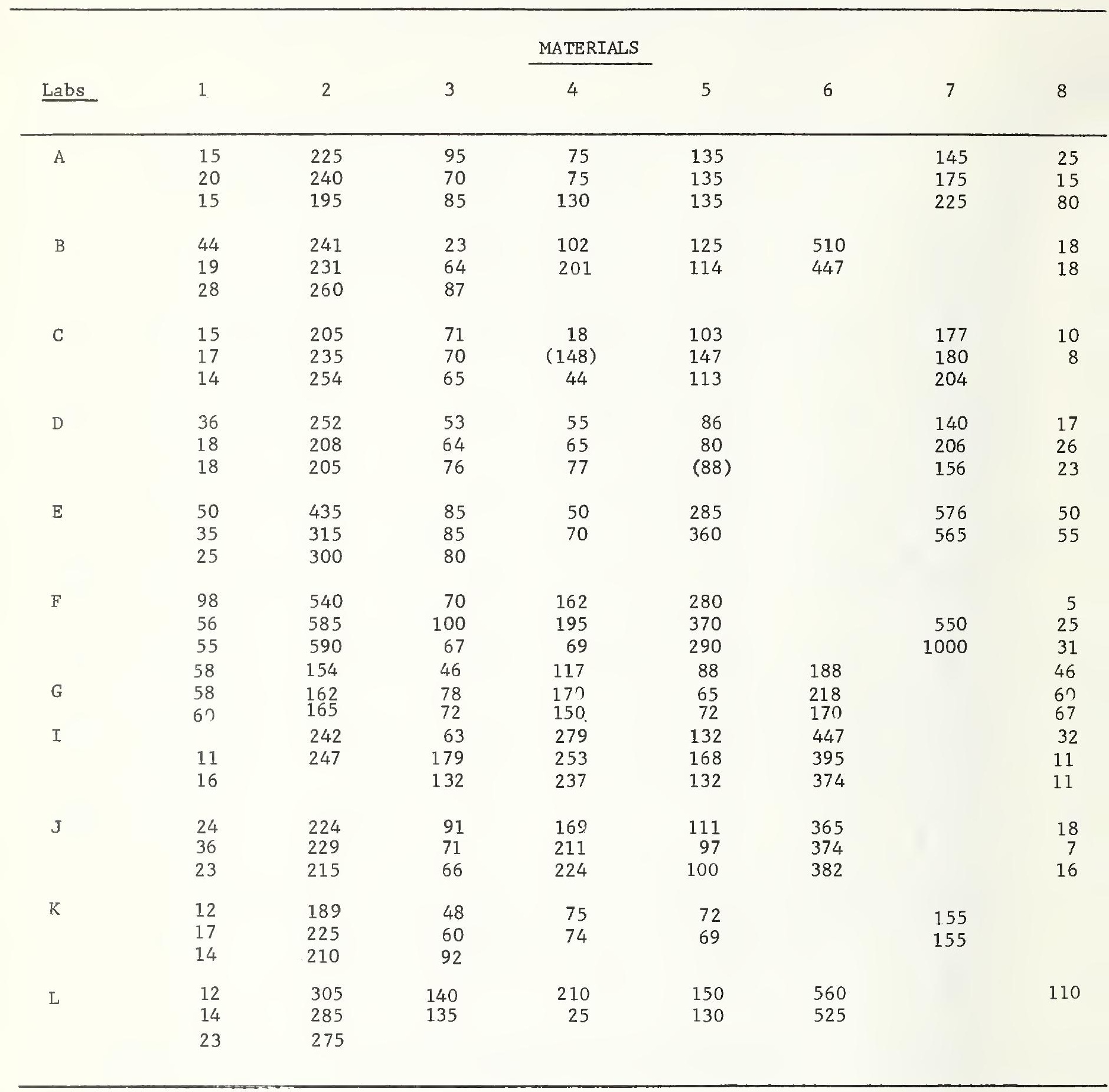

a/ Units based on red oak $=100$. 


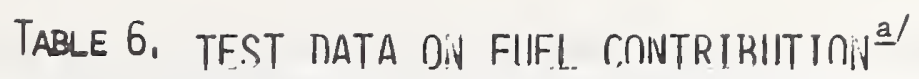

\begin{tabular}{|c|c|c|c|c|c|c|c|c|}
\hline Labs & 1 & 2 & 3 & $\frac{\text { MATERIALS }}{4}$ & 5 & 6 & 7 & 8 \\
\hline A & $\begin{array}{l}15 \\
10 \\
10\end{array}$ & $\begin{array}{l}0 \\
0\end{array}$ & $\begin{array}{l}85 \\
85\end{array}$ & $\begin{array}{l}20 \\
20 \\
30\end{array}$ & $\begin{array}{l}35 \\
40 \\
40\end{array}$ & & $\begin{array}{l}60 \\
70 \\
70\end{array}$ & $\begin{array}{l}15 \\
35 \\
25\end{array}$ \\
\hline B & $\begin{array}{l}12 \\
20 \\
13\end{array}$ & $\begin{array}{l}0 \\
0 \\
0\end{array}$ & $\begin{array}{l}24 \\
41 \\
56\end{array}$ & $\begin{array}{l}10 \\
32\end{array}$ & $\begin{array}{l}34 \\
31\end{array}$ & $\begin{array}{l}98 \\
84\end{array}$ & & $\begin{array}{r}6 \\
13\end{array}$ \\
\hline$C$ & $\begin{array}{r}11 \\
10 \\
9\end{array}$ & $\begin{array}{r}11 \\
6 \\
9\end{array}$ & $\begin{array}{l}82 \\
51 \\
72\end{array}$ & $\begin{array}{l}28 \\
14 \\
19\end{array}$ & $\begin{array}{l}48 \\
57 \\
64\end{array}$ & & $\begin{array}{l}61 \\
63 \\
66\end{array}$ & $\begin{array}{l}29 \\
29\end{array}$ \\
\hline D & $\begin{array}{r}0 \\
18 \\
18\end{array}$ & $\begin{array}{l}0 \\
0 \\
0\end{array}$ & $\begin{array}{l}60 \\
40 \\
55\end{array}$ & $\begin{array}{l}19 \\
20 \\
20\end{array}$ & $\begin{array}{c}45 \\
70 \\
(26)\end{array}$ & & $\begin{array}{l}50 \\
72 \\
52\end{array}$ & $\begin{array}{l}29 \\
13 \\
28\end{array}$ \\
\hline$E$ & $\begin{array}{l}0 \\
0 \\
1\end{array}$ & $\begin{array}{r}5 \\
10 \\
10\end{array}$ & $\begin{array}{l}55 \\
40 \\
40\end{array}$ & $\begin{array}{l}15 \\
15\end{array}$ & $\begin{array}{l}55 \\
55\end{array}$ & & $\begin{array}{l}80 \\
80\end{array}$ & $\begin{array}{l}15 \\
40\end{array}$ \\
\hline$G$ & $\begin{array}{r}12 \\
3 \\
12\end{array}$ & $\begin{array}{r}2 \\
14 \\
9\end{array}$ & $\begin{array}{l}46 \\
34 \\
48 \\
30 \\
55 \\
80\end{array}$ & $\begin{array}{r}3 \\
3 \\
5 \\
45 \\
25 \\
45\end{array}$ & $\begin{array}{l}43 \\
46 \\
38 \\
45 \\
81 \\
73\end{array}$ & $\begin{array}{l}96 \\
97 \\
92\end{array}$ & $\begin{array}{l}54 \\
58\end{array}$ & $\begin{array}{r}4 \\
11 \\
16 \\
63 \\
46 \\
56\end{array}$ \\
\hline I & $\begin{array}{l}33 \\
37 \\
38\end{array}$ & 11 & $\begin{array}{l}133 \\
171 \\
154\end{array}$ & $\begin{array}{l}48 \\
62 \\
57\end{array}$ & $\begin{array}{l}81 \\
97 \\
94\end{array}$ & $\begin{array}{l}187 \\
148 \\
156\end{array}$ & & $\begin{array}{r}56 \\
3 \\
19\end{array}$ \\
\hline $\mathrm{J}$ & $\begin{array}{l}0 \\
0 \\
0\end{array}$ & $\begin{array}{l}0 \\
0 \\
0\end{array}$ & $\begin{array}{l}44 \\
34 \\
53\end{array}$ & $\begin{array}{r}8 \\
9 \\
10\end{array}$ & $\begin{array}{l}25 \\
20 \\
31\end{array}$ & $\begin{array}{l}76 \\
80 \\
71\end{array}$ & & $\begin{array}{r}15 \\
2 \\
6\end{array}$ \\
\hline $\mathrm{K}$ & & $\begin{array}{l}5 \\
2\end{array}$ & $\begin{array}{l}50 \\
40 \\
52\end{array}$ & $\begin{array}{r}6 \\
14\end{array}$ & $\begin{array}{r}16 \\
6\end{array}$ & & $\begin{array}{l}27 \\
71\end{array}$ & \\
\hline L & $\begin{array}{l}11 \\
13 \\
12\end{array}$ & $\begin{array}{l}21 \\
19 \\
22\end{array}$ & $\begin{array}{l}121 \\
125\end{array}$ & $\begin{array}{l}16 \\
10\end{array}$ & $\begin{array}{l}62 \\
77\end{array}$ & $\begin{array}{r}107 \\
98\end{array}$ & & 41 \\
\hline
\end{tabular}

a/ Un1ts based on red oak $=100$. 
Table 7. Results of Specimen Molsture, Flame Spread, Fuel Contribution, and Smoke on Red Oak Supplied by NBS

Lab. $\frac{\text { Moisture }}{\text { Method/percent }} \frac{\text { Flame Spreadb/ }}{\text { Time, min. FSC }}$ Smoke $\quad$ Fuel

A

\begin{tabular}{|c|c|c|}
\hline 6.4 & 93 & 100 \\
\hline 6.1 & 95 & 70 \\
\hline
\end{tabular}

B

4.3

5.5

100

112

101

4.3

5.7

98

95

103

4.5

5.7

98

90

89

C

6.5

6.1

95

74

99

6.5

5.7

98

64

92

6.6

5.7

98

38

91

D

W 5.9

7.7

86

120

86

5.8

7.1

89

109

87

6.0

6.3

94

101

$\begin{array}{lll}E & P & 6.5 \\ & 6.5\end{array}$

5.9

97

95

99

5.7

5.8

98

98

89

110

102

98

102

F

5.8

5.1

5.3

108

54

104

6.4

5.7

98

92

92

100

94

91

G

6.5

5.2

105

5.8

98

99

102

100

6.7

5.5

100

102

99

100

6
7
6

5.5

100

5.3

104

135

140

5.7

98

J W

6.7

5.2

106

5.4

102

6.4

5.9

97

94

100

99

107

100

$\begin{array}{lll}\mathrm{K} & \mathrm{P} & 6.7\end{array}$

5.5

100

113

90

6.6

5.5

100

108

97

98

$\begin{array}{lll}\mathrm{L} & \mathrm{P} & 7.3\end{array}$

6.8

90

56

80

6.8

6.0

96

85

95

a/ $\mathrm{P}=$ Conductivity moisture probe.

b / Based on E 84, time to end of tunnel.

c) Based on calibration standard of each laboratory using red oak $=100$. 


\subsection{Statistical Results}

One of the purposes of the interlaboratory evaluation of the test method was to determine the degree of uncertainty of the resultant data. Table 8 summarizes the results on flame spread, smoke, and fuel contribution in terms of the means, ranges, and the within-laboratory (repeatability) and between laboratory (reproducibility) coefficients of variations for each material. The repeatability and reproducibility data are given in terms of the expected precision of a single determination within a single laboratory and a single determination among the laboratories respectively. The values were derived from a "betweenwithin" analysis of variance made separately for each material [5,8]. A weighting factor was used to normalize results between two and three replicate runs. The analysis is based on all the data from the 11 laboratories except the 4 values in parentheses in Table 4 which resulted from errors in test procedure (the incorrect surface of Material 非 was exposed in one case and asbestoes papers were used on the furnace floor in the other cases). Because of the wide scatter in numerical values on FSC for material 非, data less than 77 were excluded from the calculation for coefficient of variation.

It is meaningless to express an overall reproducibility and repeatability for all materials tested because the results appear to be material dependent. For most materials, reproducibility would improve only slightly If it were based on the averages of 2 or 3 replicate runs. For a method of converting the statistical result to that based on more than single tests, see Appendix E. 


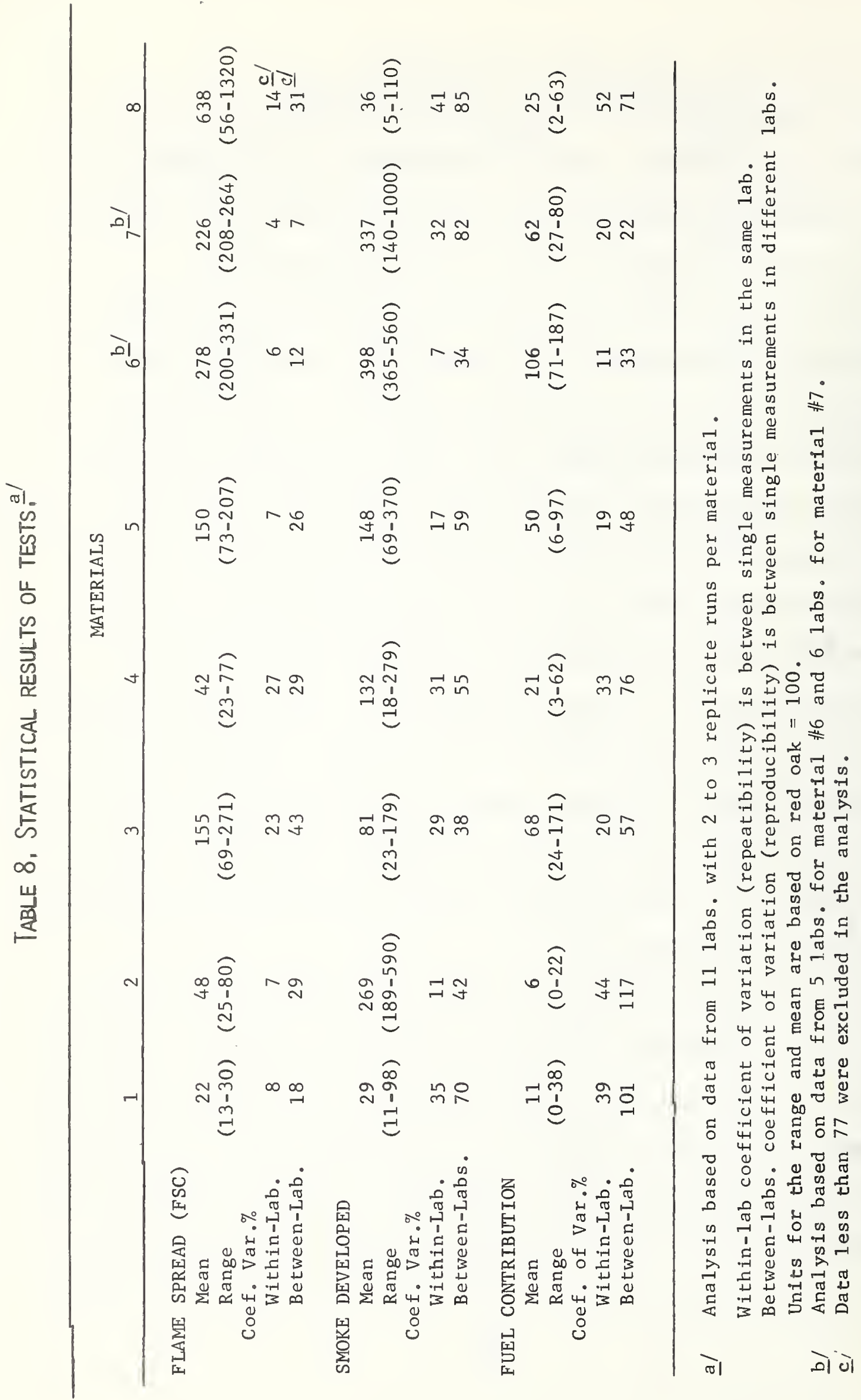




\subsection{The Use of Other Formulas for FSC Calculation}

Because of anomalies in some test results caused by the application of four sets of formulas in the calculation of FSC, many methods have been proposed to avoid the problem. The method in the present standard calls for the use of four completely different methods of calculation depending on the time and on whether or not the flame spread reaches the far end. As a result some normal measurement errors are exaggerated by the discontinuity in going from one formula to another. See Appendix D.

One of the earlier proposed methods, for example, is based on "rate", FSC $=28.2 \frac{\mathrm{d}}{\mathrm{t}}$, where $\mathrm{d}$ is maximum distance burned ( $\mathrm{ft}$, ) and $t$ is the corresponding time (min.) to reach the maximum distance regardless of whether or not the flame reaches the end of the tunnel.

A more recent (Dec. 1972) proposed method made by the task group on the E-84 calculation method under ASTM Committee E5.04 is based on the following "area" formulas:

$$
\begin{array}{ll}
\text { FSC }=0.564 \mathrm{~A} & \text { for } A \leq 97.5 \mathrm{ft} \text { min. } \\
\text { FSC }=5362 /(195-\mathrm{A}) & \text { for } A>97.5 \mathrm{ft} \text { min. }
\end{array}
$$

where $A$ is the integrated area under the curve based on the flame or burned front distance as a function of time on the last $191 / 2 \mathrm{ft}$ of the specimen during the 10 minute test period. Of several alternate calculation methods, this method has the advantage of minimizing differences in results obtained from the present standard and the proposed method.

If this method is adopted, it is essential to define flame or burned front in the standard more explicitly, since its correct interpretation is much more critical in determining the result than that in the present standard. The flame front or flame spread is not defined in the present 


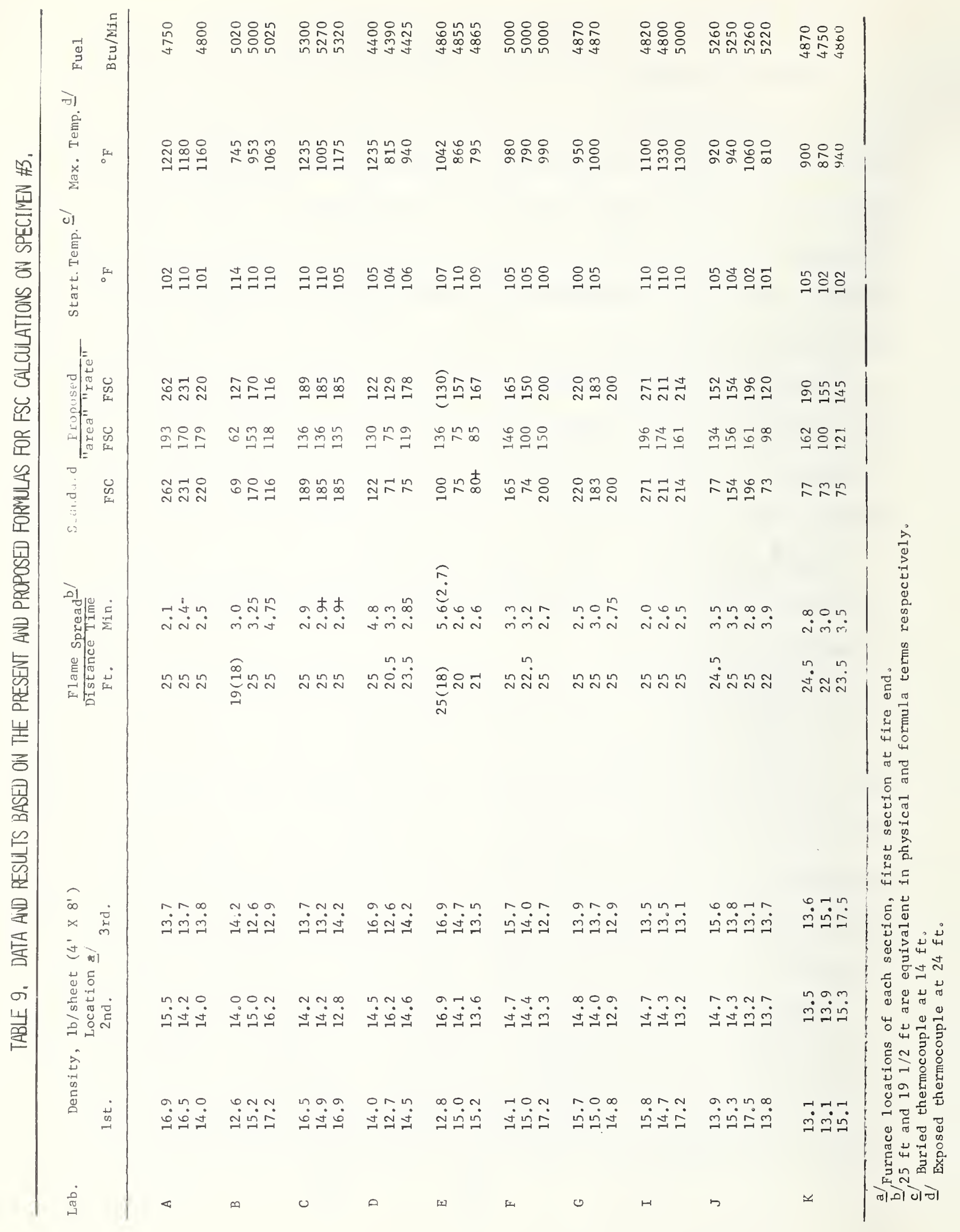


standard. Various operators have different techniques for judging the front. Their judgements are often complicated by the difficulties in viewing through heavy smoke deposits on windows from certain specimens. These sources of interpretation and reading errors require study. The anomaly from using the standard calculation is particularly noticeable in the results on material 非, plywood. Flame spread data for this specimen are used as an example to compare the results of applying each method of calculation. Table 9 presents data on material 非, giving specimen density, furnace position of each specimen, time and distance of maximum travel, and results of FSC by the standard and two proposed methods of calculations. Input fuel rate and starting temperature were included to show the normal test variations, also typical in tests of other materials.

\section{Discussion}

\subsection{Tunnel Construction Variables}

The differences of detail in construction and measurement techniques among laboratories, as shown by Table 3, are obvious. The relative effect of any of the variables (i.e. smoke meter location, windows, velocity control etc.) on the results is difficult to assess by looking at these data alone. However, gross effects not easily masked by other variables can sometimes be detected. For example, the consistently high or low smoke results from Laboratories D, E, F and G on several materials may have been caused by differences in their smoke measuring system relative to that of the other laboratories as shown in table 3 . Leakage may also contribute to the low values for laboratory $G$ since it did not follow the leak-test procedures. 
The smoke value in the standard is determined by the ratio of the area under the smoke obscuration curve for the specimen and for the red oak reference. Since both specimen and reference are subjected to the same exhaust duct and photometer measurement system, the effect of any existing bias should in principle, be compensated. This is not valid for two reasons. One is due to the fact that smoke concentration (mass or optical) is not proportional to obscuration but to the log of reciprocal transmission. Because of the compression at the higher end of the $\log$ scale, the concentration ratio of two smokes will vary depending on the actual magnitude of the smoke value for the reference material. Since the level of obscuration from the reference material is determined by the concentration of smoke reaching the photometer and by its path length, unequal losses in ducts resulting from differences in design become important.

A second factor which may explain the inadequacy of using red oak for a smoke reference is the mechanism of smoke 1oss. For example, the coagulation and decay of wood smoke which consists mainly of condensed liquids is extremely temperature dependent whereas the decay of synthetic carpet smoke (mostly carbon particulates) is much less temperature sensitive but coagulation-time dependent. Therefore, a tunnel with a cold and short duct, say, will result in a low reference value for red oak and thus give a higher ratio for carpet smoke. On the other hand, a hot and long duct will tend to increase the time for coagulation losses but not condensation 1osses. This will result in a lower value for carpet smoke.

Specimen 非3, plywood, has the lowest variability (between-laboratories) in smoke among the materials tested. Based on the reasons mentioned 
above this is not unexpected. The normalizing factor of using a reference material is more effective when the specimen and reference smokes are similar in nature. This also indicates the need to study the problem of selecting reference materials.

There is general agreement among the laboratory operators on attributing part of the large variability of smoke results to the lack of a specification on the smoke photometer and its location. However, we believe that to attain reasonable reproducibility in test results, the smoke measurement system including exhaust duct length, insulation, photometer path length, instrument range, etc. should be standardized in all tunnels.

The causes of variability in fuel contribution is not clear. For example, laboratories that rank first or second in terms of high value in fuel contribution for all materials are Laboratories G, I and L. These are 3 of the 4 tunnels using the single-type windows and without turbulence bricks. The bricks are not required by the present standard.

Certainly the lack of uniformity in thermocouple type, location, and mounting method among tunnels is a factor contributing to the variability. Perhaps in future modifications several thermocouples should be used in each tunnel to minimize the effect of high temperature gradients which make the location of a single thermocouple very critical. A means to minimize soot deposit on the junction of the thermocouple is also needed. This should improve the reproducibility of the test method.

In addition to the factors mentioned, some operators attribute the variability of smoke and fuel developed to the physical condition of 
Table 10. Mean FSC for Each Material and Laboratory

\begin{tabular}{l|rrrrrrrr}
\hline & \multicolumn{7}{|c}{ Materials } \\
\cline { 2 - 7 } & 1 & 2 & 3 & 4 & 5 & 6 & 7 & 8 \\
\hline A & 24 & 46 & 238 & 32 & 152 & & 251 & 1170 \\
B & 16 & 39 & 118 & 47 & 157 & 275 & & 75 \\
C & 26 & 70 & 186 & 33 & 154 & & 214 & 540 \\
D & 23 & 47 & 89 & 36 & 144 & & 217 & 980 \\
E & 27 & 72 & 85 & 32 & 147 & & 218 & 560 \\
F & 20 & 39 & 146 & 40 & 173 & & 229 & 482 \\
G & 16 & 48 & 201 & 48 & 107 & 228 & & 574 \\
I & 23 & 27 & 232 & 49 & 197 & 311 & & 950 \\
J & 26 & 39 & 142 & 42 & 196 & 293 & & 271 \\
K & 23 & 57 & 75 & 28 & 73 & & 228 & \\
L & 21 & 57 & 195 & 56 & 390 & 281 & & 1000 \\
\hline
\end{tabular}

Tadle 11. FSC Ranking of Materials Ly Each Laboratorya-

\begin{tabular}{|c|c|c|c|c|c|c|c|c|}
\hline \multirow{2}{*}{ Lab } & \multicolumn{8}{|c|}{ Materials } \\
\hline & 1 & 2 & 3 & 4 & 5 & 6 & 7 & 8 \\
\hline$A$ & 1 & 3 & 5 & 2 & 4 & & 6 & 7 \\
\hline B & 1 & 2 & 5 & 3 & 6 & 7 & & 4 \\
\hline C & 1 & 3 & 5 & 2 & 4 & & 6 & 7 \\
\hline D & 1 & 3 & 4 & 2 & 5 & & 6 & 7 \\
\hline$E$ & 1 & 3 & 4 & 2 & 5 & & 6 & 7 \\
\hline$F$ & 1 & 2 & 4 & 3 & 5 & & 6 & 7 \\
\hline$G$ & 1 & 2 & 5 & 3 & 4 & 6 & & 7 \\
\hline I & 1 & 2 & 5 & 3 & 4 & 6 & & 7 \\
\hline $\mathrm{J}$ & 1 & 2 & 4 & 3 & 5 & 6 & & 7 \\
\hline K & 1 & 3 & 5 & 2 & 4 & & 6 & \\
\hline$L$ & 1 & 2 & 4 & 3 & 6 & 5 & & 7 \\
\hline
\end{tabular}

a/Based on mean of 3 or 2 runs. 
ledges and covers of the tunnel as well as to the size of the flame as a result of burner variation.

\subsection{Results of Flame Spread Measurement (FSC)}

Tables 10 and 11 give the average value of FSC for each material and the rank ordering of the materials by each laboratory respectively. It is unrealistic to expect good agreement in ranking between materials 非 2 and $\# 4$ and between materials $\# 3$ and 5 because of the close proximity of FSC values. Otherwise most laboratories agreed on the relative ranking of the materials tested.

In terms of code classification based on NFPA Code 101, (1970) there is good agreement among laboratories on five of the materials (Materials 2, 4, 5, 6 and 7) in Table 12. But the discrepancy on the other three materials, though explainable, may be of the type that has caused concern in the past to material producers who must meet code requirements which use specific ranges of values for material classification.

The variability of the FSC for the carpets tested does not appear excessive relative to other types of materials. The poorest in terms of reproducibility is material 非, a shag nylon, where the average for the lowest laboratory (except laboratory $\mathrm{K}$ ) was 107 and for the highest laboratory was 197. There were two individual runs in which the values were slightly over 200, which would have disqualified it as a Class C material. Data on material 非 from laboratory L is excluded because of the use of asbestos paper on the furnace floor. The value of Lab. K would become 111 and closer to the mean, if the new method of calculation based on "rate" were adopted. 
TABLE 12, Code Classification of Materials a-/

\begin{tabular}{|c|c|c|c|c|c|c|c|c|}
\hline \multirow{2}{*}{ Lab } & \multicolumn{8}{|c|}{ Materials } \\
\hline & 1 & 2 & 3 & 4 & 5 & 6 & 7 & 8 \\
\hline A & A & B & D & B & C & & & $E$ \\
\hline B & $A$ & B & $C$ & B & C & $D$ & & B \\
\hline C & B & B & $C$ & B & C & & D & $E$ \\
\hline$D$ & $A$ & B & C & B & C & & D & $E$ \\
\hline$E$ & B & B & $C$ & B & C & & $D$ & $E$ \\
\hline$F$ & $A$ & B & C & B & C & & $D$ & $D$ \\
\hline$G$ & $A$ & B & $D$ & B & C & D & & $E$ \\
\hline I & $A$ & B & D & B & C & D & & $E$ \\
\hline$J$ & $B$ & B & C & B & C & $D$ & & $D$ \\
\hline K & $A$ & B & B & B & B & & D & \\
\hline$L$ & $A$ & B & C & B & D & $D$ & & $E$ \\
\hline
\end{tabular}

a/ Based on average flame spread (FSC) of 3 runs

NFPA Code 101, Life Safety Code Classification (1970)

$$
\begin{array}{ll}
A=0-25 \text { FSC } & D=201-500 \text { FSC } \\
B=26-75 \text { FSC } & E=\text { over } 500 \\
C=76-200 \text { FSC } &
\end{array}
$$


The carpet results also indicate the effect of including the underlayment in the test. Identical carpet specimens (非 and 非) gave an average flame spread classification of only 42 without and 278 with underlayment. This points out the need for knowing whether underlayment was used in the reported test results, and whether it will be used in the proposed application.

The variability of FSC for material 非 (fiber glass batt) is numerically small. A level of 25 is used as a cut off point between Class $A$ and $B$ by most code authorities. Six laboratories rate the material in Class $A$. Two rated it in Class $B$, and three rated it in $A$ or $B$ depending on the particular run.

\subsection{Effect of Using a Single Formula for FSC Calculation}

The between-laboratory variability of FSC results for material 非, plywood panel, was of the order of $43 \%$. The variability is exaggerated by using the two formulas required in the method for calculating the FSC, depending on whether or not the flames traveled the full length of the specimen. Undoubtedly some of the variability was a result of variation in specimen density, (Range 0.40 to $0.531 \mathrm{~b} / \mathrm{ft}^{2}$ ) a normal range for a commercial product of this type. For example, the 1st and 2nd runs of Laboratory $\mathrm{J}$ in Table 9 were similar in rate, but because the flame front stopped within a half foot of the end for the first run, the FSC value was 77 , compared with 154 for the second run where the flame reached the end of the specimen. In spite of the difference, however, both would be Class C (76-200) under the NFPA Code 101 Life Safety Code Classification. Table 9 also shows that in some cases (i.e. Laboratories $\mathrm{D}, \mathrm{F}, \mathrm{J})$ the same material could be classified as Class $B$ 


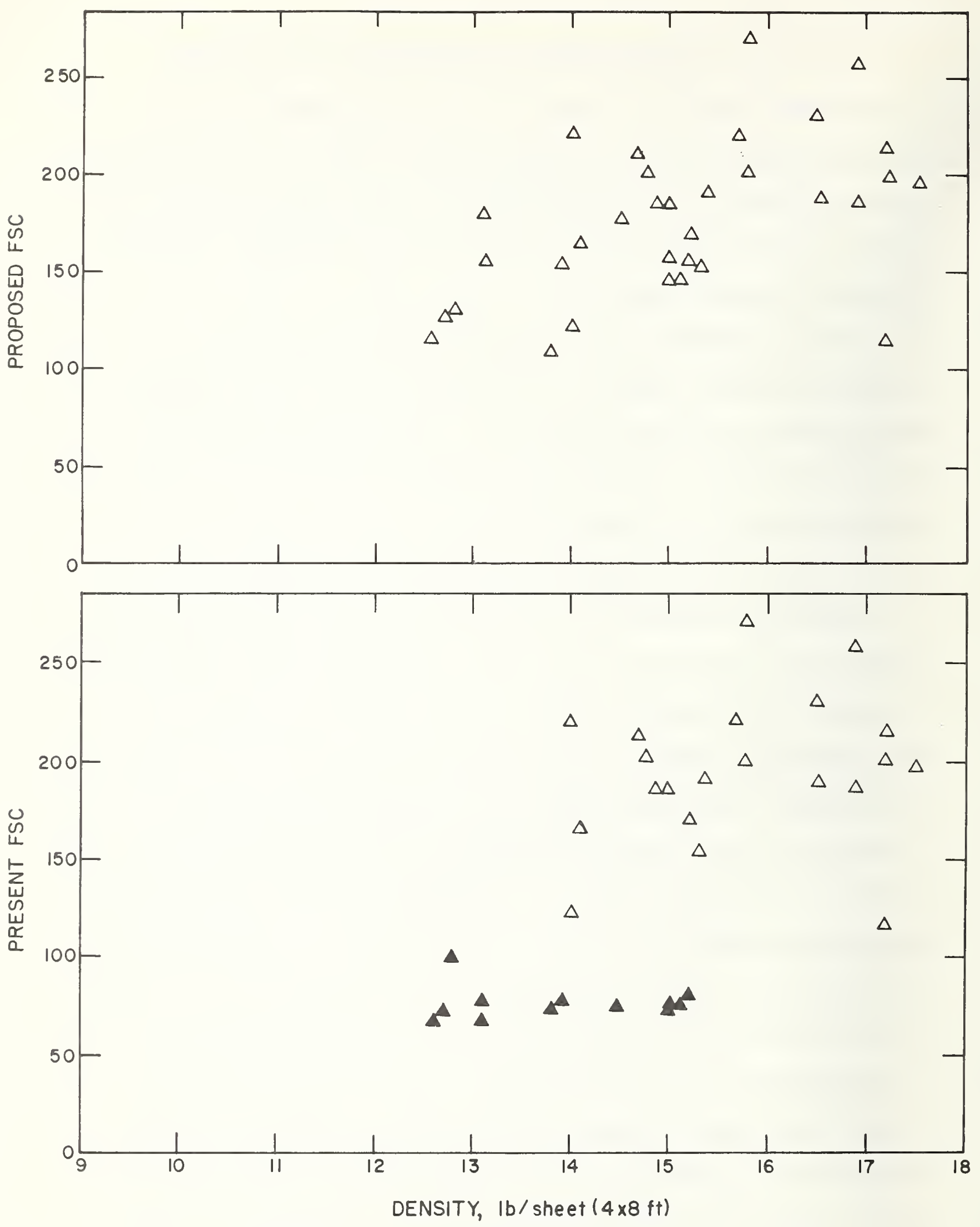

FiguRE 8. FSC AS FUNCTION OF DENSITY OF SPECIMEN \#3 BASED ON THE PRESENT (BOTTOM) AND "RATE" (TOP) FOPMULAS, $\triangle$ DATA AFFECTED BY CHANGE OF FORMULA, 
(26-75) or Class C (76-200) even within a single laboratory under normal testing variability caused by the use of 2 sets of formulas. For this reason material producers have in the past frequently questioned the precision of the test.

If the "rate" or "area" method was used in the calculation, as shown in Table 9, the exaggerated scatter in results would be minimized. This is further illustrated in Figure 8 where the FSC results for the plywood panels are plotted as a function of density of specimen at the burner section of the tunnel using the present and the single "rate" methods for FSC calculation. Observations by others [6] show that the panel section at the fire end has proportionately more effect on the result.

Figure 8 shows the limited dependence of flame spread on density of the panel. Specimens less than about $13 \mathrm{lb} /$ panel did not produce sufficient fuel for a complete burn to the end (FSC $<100)$. The data spread of FSC for the 14-15 1b/panel group is wider than that of the 15-17 1b/panel group based on the present two-formula method. An artificial barrier near FSC of 70. is evident in Figure 8 (bottom). Results based on a single formula as shown in Figure 8 (top) appear to be more credible. Either of the two proposed methods of calculations will improve on the consistency of test results compared to the present formulas.

The complexity of the problem in using the tunnel data for the evaluation of flame spread hazard is further shown in Figure 9. It shows the flame spread distance as a function of time for each of the materials tested based on typical runs. FSC values based on the Standard 


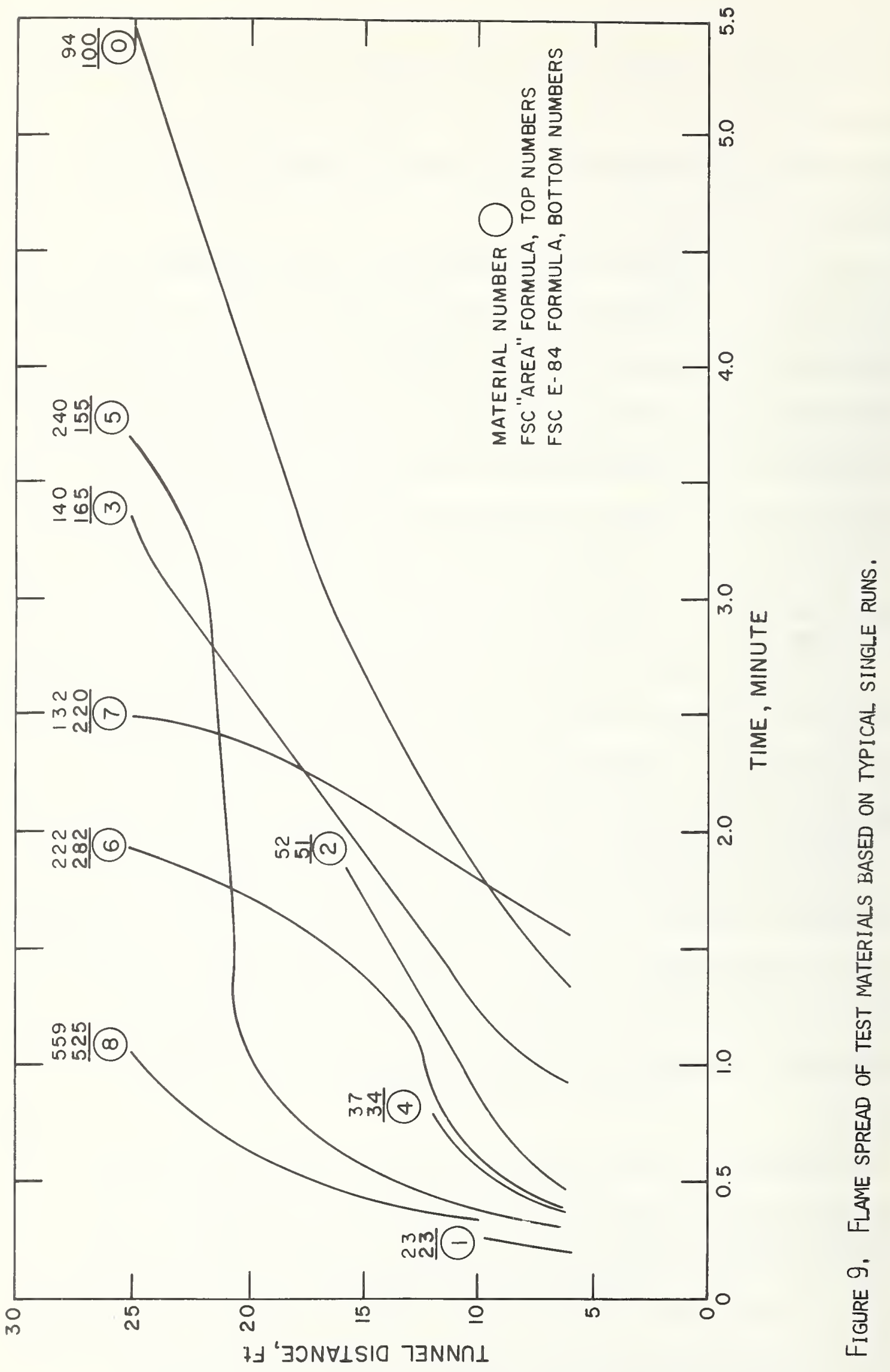


and one proposed method (area under the curve) of calculations are also given. Materials have different induction periods, and varying flame front velocities as well as different times of arrivals at the end of the tunnel. The factors used to formulate a rating method such as FSC may necessarily be arbitrary - but good repeatability of test results should be an important criterion.

\section{Conclusions}

Based on the test results from eleven (11) laboratories using the ASTM E 84 (tunne1) method involving 240 tests on 9 (8+ reference) materials, observations and measurements of tunnel facilities, and discussion with operators, the following conclusions are presented.

1. For a randomized sample of red oak, the standard reference material, 10 out of 11 laboratories obtained results in fair agreement with their previous calibration defined as 100 for flame spread classification (FSC) and fuel contribution. Individual values, from the 10 laboratories ranged from 90 to 108 for FSC and from 80 to 140 for fuel contribution. For smoke developed the agreement is not as good; it ranged from 38 to 135 .

2. The median test reproducibilities in terms of the between-laboratory coefficient of variation for the eight (8) materials tested are as follows: Flame spread classification, 27\% (ranged from 7 to $43 \%$ ) Smoke developed $57 \%$ (ranged from 34 to $85 \%$ ) Fue1 contribution $64 \%$ (ranged from 22 to $117 \%$ ) 
3. The test reproducibility of the 4 carpet systems tested in terms of coefficient of variation for flame spread (FSC) ranged from 7 to $29 \%$ calculated on the basis of single tests in different laboratories.

4. Use of different calculation methods for FSC improved the reproducibility of results for the plywood. Similar improvement is expected on other borderline materials.

5. There are significant variations in construction and in measurement techniques among tunnels because of the lack of detailed specification in the test method standard. It is reasonable to assume that these variations affect the reproducibility of the test results.

6. The rating of material using the NFPA code 101 (1970) classification method (i.e. A, B, C, D and E) shows good agreement among laboratories on five of the materials and poor agreement on the other three materials.

\section{Recommendations}

1. More detailed specifications, improved design, and standardization in the construction and operation of tunnel furnaces are needed in order to improve reproducibility in the measurement of flame spread, smoke and fuel contribution. This would serve all concerned including code 
officials, consumers, producers and the testing laboratories.

2. Tunnel operators should meet, discuss and implement solutions to the interlaboratory variability problem. Task groups in ASTM E 5.04 have been formed to examine various facets of the problems. Since recommendations for improvement are urgently needed, concurrent study by others should be encouraged and supported.

3. Organizations who use the test results from the ASTM E 84 test method for regulatory purposes should be consulted. Their views and legal authority are needed in order to support, supplement, expedite and enforce recommendations from the task groups studying the problem.

4. The reproducibility of measurement of smoke and fuel contribution reported in this round robin is not acceptable. Alternative methods for smoke and potential heat measurement are available. 
9. Acknowledgement

The participating laboratories performed all tests without compensation. The valuable contributions in terms of. advice and generous cooperation from the staff of each laboratory are gratefully acknowledged. The Carpet and Rug Institute donated all the carpet specimens. Owens-Corning Fiberglas, Hardwood Plywood Manufacturers Association, and Armstrong Cork Company provided the necessary fiber glass batt, plywood panel, and sheet vinyl, flooring specimens, respectively. Consultation on statistical problems was provided by Dr. J. Mandel, Statistical Consultant, Institute of Material Research, National Bureau of Standards.

In addition to NBS, the following organizations provided financial support to the project:

Health Services and Mental Health Administration-HEW

Public Building Service-General Services Administration

Naval Facilities and Engineering Command

Veterans Administration

The draft of this report was made available to the participating laboratories for comment and data verification. Most comments were useful and were accepted. Others, especially those on the influence of tunnel variables on results, though valuable, are not considered within the scope of this paper, but would be available to the task groups. 


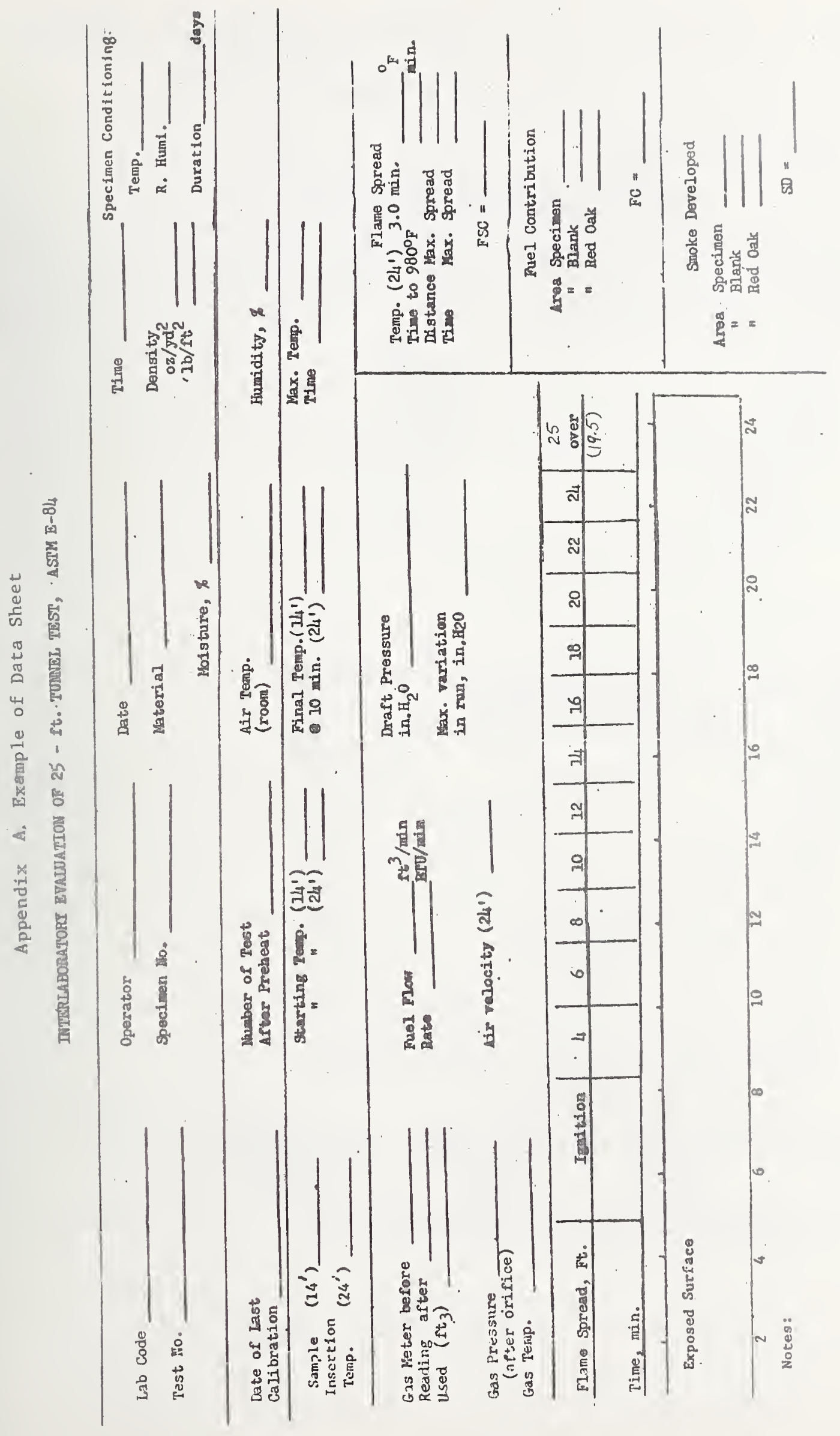




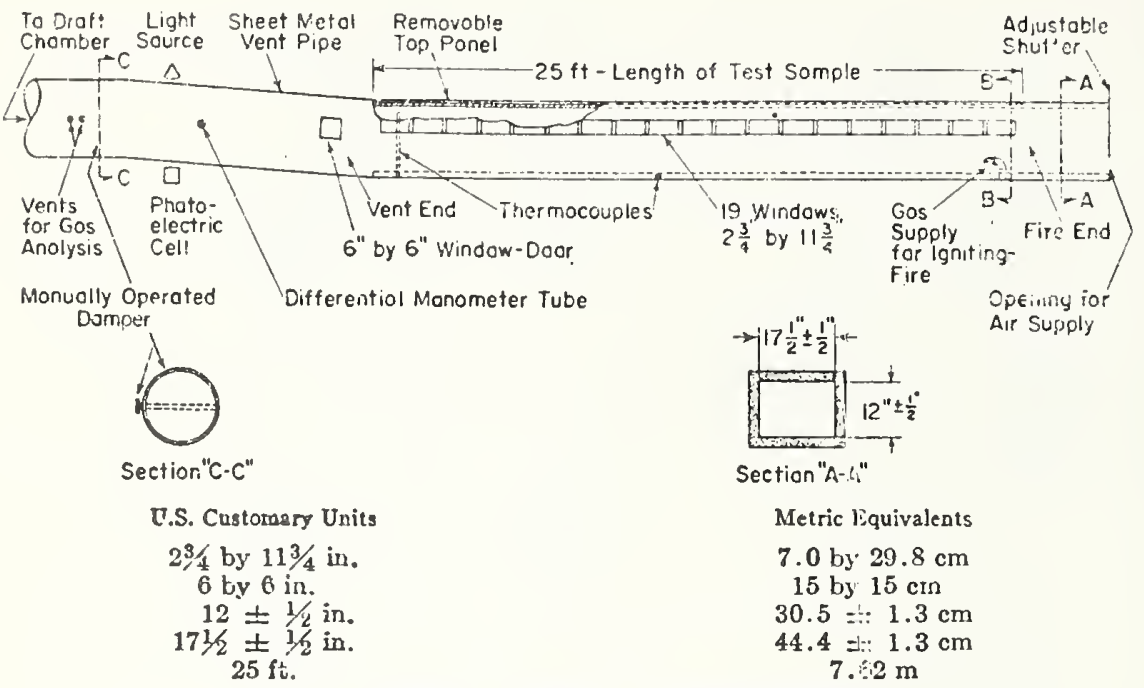

FIG. 1-TesțFurnace Showing Critical Dimensions.

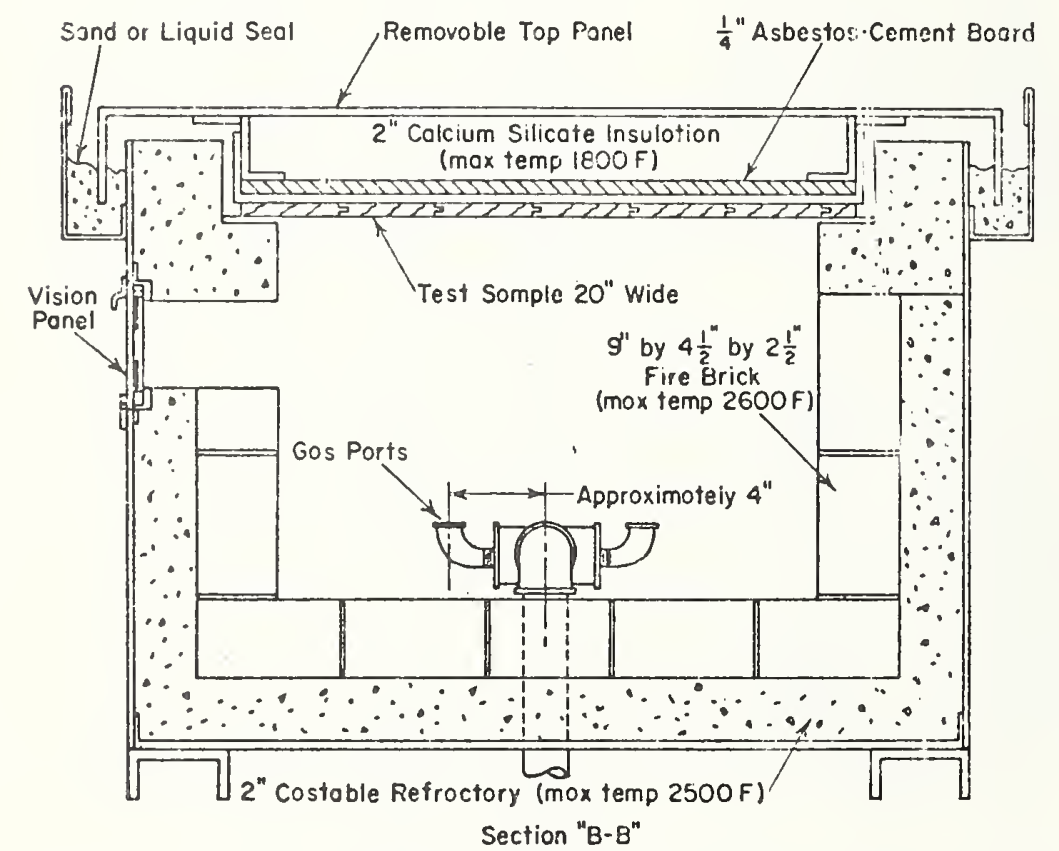

\begin{tabular}{cc||cc} 
I.S. Customary Units & Metric Equivalents & U.S. Customary Linits & Metric Equivalents \\
$1 / 4$ in. & $6.3 \mathrm{~mm}$ & $8 \mathrm{by} 41 / 2 \mathrm{byr} 21 / 2 \mathrm{in}$. & $23 \mathrm{by} 11.5 \mathrm{by} 6.5 \mathrm{~cm}$ \\
$2 \mathrm{in.}$ & $5.1 \mathrm{~cm}$ & $1800 \mathrm{~F}$ & $982 \mathrm{C}$ \\
$4 \mathrm{in.}$ & $10.2 \mathrm{~cm}$ & $2500 \mathrm{~F}$ & $1371 \mathrm{C}$ \\
$20 \mathrm{in}$ & $50.8 \mathrm{~cm}$ & $2600 \mathrm{~F}$ & $1427 \mathrm{C}$
\end{tabular}

FIG. 2-Test Furnace Showing Critical Dimensions (Section "B-B"). 
Appendix C. Task Groups Under ASTM E 5.04 to Study Revision of E 84 Test Method Standard (organized between 1967 and Oct. 1972):

1. Specimen Mounting Methods for $\mathrm{E} 84$.

2. Flame Spread Calculation Methods for E 84.

3. Revision of the Scope in E 84. (To or Not to include carpets).

4. Evaluation of Procedures on Smoke Measurement in E 84.

5. E 84 Tunnel Operator's Group.

6. Criteria for Evaluation of Laboratories Conducting E 84 Tests. 
Appendix D. Method of Flame Spread Classification (FSC)

Under the Current E 84-70 Standard

6. Classification

6.1 The flame spread classification (FSC) shal1 be determined as follows:

6.1.1 For materials on which the flame spreads $19-1 / 2 \mathrm{ft}$ $(5.94 \mathrm{~m}):$

6.1.1.1 In 5-1/2 min or less, the classification shall be 100 times 5-1./2 min divided by the time in min ( $t$ ) in which the flame

1. spreads $19-1 / 2 \mathrm{ft}(5.94 \mathrm{~m}),(\mathrm{FCS}=550 / \mathrm{t})$.

6.1.1.2 In more than 5-1/2 min but not more than $10 \mathrm{~min}$, the classification shall be 100 times 5-1/2 min divided by the time in min ( $t$ ) that the flame spreads $19-1 / 2 \mathrm{ft}(5.94 \mathrm{~m})$, plus $1 / 2$ the

2. difference of 100 minus this result, $(\mathrm{FSC}=50+275 / \mathrm{t})$.

6.1.2 For materials on which the flame spreads less than 19-1/2 ft $(5.94 \mathrm{~m})$, and then ceases to continue or recedes in a 10 min test period.

6.1.2.1 When the extreme flame spread distance (d) is more than $13-1 / 2 \mathrm{ft}(4.11 \mathrm{~m})$ and less than $19-1 / 2 \mathrm{ft}(5.94 \mathrm{~m})$, the classification shal1 be 100 times 5-1/2 min times the distance (d) divided by $19-1 / 2 \mathrm{ft}(5.94 \mathrm{~m})$ times $10 \mathrm{~min}, \mathrm{plus} 1 / 2$ the difference

3. of 100 minus this result, (FSC $=50+1.41 \mathrm{~d})$ FSC (metric) $=50+4.62 \mathrm{~d})$.

6.1.2.2 When the extreme flame spread distance (d) is $13-1 / 2 \mathrm{ft}$ $(4.11 \mathrm{~m})$ or less, the classification sha11 be 100 times the distance

4. (d) divided by $19-1 / 2 \mathrm{ft}(5.94 \mathrm{~m}),($ FSC $=5.128 \mathrm{~d})($ FSC (metric $)=16.84 \mathrm{~d})$. 
Appendix E. Calculation of Reproducibility Based on the Averages of Replicate Tests

$$
\begin{aligned}
& B m=\sqrt{B_{s}^{2}-W s^{2}+\frac{W s^{2}}{m}} \\
& W m=\frac{W s}{\sqrt{m}}
\end{aligned}
$$

where $\mathrm{Bm}=$ Between-labs, coefficient of variation, (c.v.), between averages of m replicates in different labs.

Bs $=$ Between-lab. C.V., between single tests in different labs.

Wm $=$ Within-lab. C.V., based on the averages of $m$ tests in a single lab.

Ws $=$ Within-lab C.V. based on single tests in single lab.

$\mathrm{m}$ = Number of replicate runs. 


\section{References}

[1] ASTM E-84-70, Standard Method of Test for Surface Burning Characteristics of Building Material, 1971 Annual Book of ASTM Standards, Part 14, American Society for Testing and Materials, Philadelphia, Pa. 1971 .

[2] C. H. Yuill, "Round Robin Tests on Tunnel Type Flame Spread Furnaces for ASTM," Southwest Research Institute, San Antonio, Texas, April 1959.

There are other correlation works between UL and one or two other laboratories.

[3] Endicott, L. E., and Bowhay, R. B., "A Statistical Evaluation of the Fire Hazard Classification Furnace (ASTM E 84-68)" Material Research and Standards 19, 10, 1970.

[4] Castino, T., Report on October 17, 1968 Meeting of Representative of Operating Tunnel Test Facilities, private communication.

[5] Brownlee, K. A., "Statistical Theory and Methodology in Science and Technology," John Wiley and Sons, Inc. (1965).

[6] Robert Robins, Hardwood Plywood Manufacturing Association, private communication, data, 5/30/72.

[7] George Armstrong, Southwest Research Institute, private communication, letter, $11 / 13 / 72$.

[8] J. Mandel and R. C. Pauli, Anal. Chem., 42, 1195, (1970). 
rorise Res-ilita (init)

II.S. DEY . OF COAMS.

DHB:BOGRPMIC DA: SHI:ET

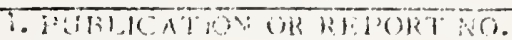

ISBSIR ? O 125

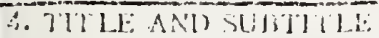

Interlaboracory Evaluetion of the Tunnel Test (ASTM E84)

Applied to Tloor Coverings

7. A.THON(S)

T. G. Lae and Clayton Huggett

9. PERF ORR:ING ORGANIZATION NAME AND ADDRESS

NATIUNAL RLIREAU OF STANDARDS

"DEP AR'TMENT OE COMMERCE

WASHINGTON, D.C. 20234

12. Sponsoring Organization Name and Address

Jepartment of Health, Education \& Welfare

Vashington, D.C. 20201

General Services Administration

Washington, D.C. 20407

15. SUPPLEMENTARY NOTES

16. A BSTRACT (A 200-nord or less factual summaty of most significant information. If document includes a significant bibliography or literature survey, mention it here.)

Results of an interlaboratory evaluation of the ASTM E 84 tunnel test method involving eleven laboratories and nine materials, including four carpets, are reported. Data on flame spread, smoke, and fuel contribution are analyzed statistically. Selected physical characteristics of each tunnel are tabulated and compared relative to specifications in the test method. The between-laboratory coefficient of variation (reproducibility) in flame spread classification (FSC) was found to range from 7 to $29 \%$ for the four carpets and from 18 to $43 \%$ for the other materials tested. The between-laboratory coefficients of variation for smoke developed and fuel contribution ranged from 34 to $85 \%$ and from 22 to $117 \%$ respectively for all materials tested. The causes of higher variability in smoke and fuel contrit:tion measurement between laboratories is not definitely known but may reasonably te attributed to variations in tunnel construction, maintenance, and operation, in the location of photometers, and in the mounting of thermocouples in different laboratories Some variability of results may possibly be due to variation in test specimens. Variation in construction and measurement techniques among tunnels may be minimized by updating the test method standard.

17. KEY WORDS (Alphabetical order, separared by semicolons)

ASTM E 84; building materials; carpets; fire tests; flame spread cests; interlaborator: evaluation; round robin; statistical analysis; test method srandard.

18. AVAILABILITY STATEMENT

$[\mathrm{X}]$ UNLIMITED.

FOR OFFICIAL. DISTRIBUTION. DO NOT RELEASE

ii) NTis.

19. SECURITY CL.ASS

(THIS REPORT)

21. NO. OF PAGES

UNCL ASSIFIED

20. SECUR ITY CI.ASS

('TIIIS PAGE)
22. Price

UNCL ASSIFIED 
